CUADERNOS DE ESTUDIOS GALLEGOS, LX Núm. 126 (enero-diciembre 2013), págs. 13-50

ISSN: 0210-847 X

DOI: 10.3989/ceg.2013.126.01

\title{
LAS PILAS DEL CASTRO DE SANTA MARIÑA DE MASIDE (OURENSE): HACIA UNA TIPOLOGÍA DE LOS LUGARES CON FUNCIÓN RITUAL EN LA EDAD DEL HIERRO DEL NW DE LA PENÍNSULA IBÉRICA*
}

\author{
Yolanda Seoane-Veiga \\ Instituto de Ciencias del Patrimonio \\ CSIC \\ Marco V. García Quintela \\ Alejandro GÜImil FARIÑA \\ Universidad de Santiago de Compostela
}

\footnotetext{
Agradecimientos a Manuel Santos y César Parcero por la lectura y sugerencias al texto; a Wajari Velásquez y Álvaro Arizaga por la ayuda en el trabajo de campo; a Antón Fernández Malde y Manuel Gago por proporcionarnos la información sobre Pedra Furada; y a Adolfo Fernández y Martiño Vázquez por sus detallados comentarios sobre la excavación del nuevo "santuario" de Armea (no hacen suya necesariamente la interpretación del lugar como "santuario"). Proyecto de investigación financiado por la Xunta de Galicia: Arqueoloxía e relixión: da Idade do Ferro á Idade Media, código 10PXIB210112PR.
} 


\section{LAS PILAS DEL CASTRO DE SANTA MARIÑA DE MASIDE (OURENSE): HACIA UNA TIPOLOGÍA DE LOS LUGARES CON FUNCIÓN RITUAL EN LA EDAD DEL HIERRO DEL NW DE LA PENÍNSULA IBÉRICA}

\section{RESUMEN}

En este artículo pretendemos detenernos con cierto detalle en las pilas que aparecen en contextos de castros de cara a evaluar su posible función religiosa. Nuestro interés se centrará en el castro de Santa Mariña de Maside (Ourense), donde existen varias rocas con pilas rectangulares y rebajes de distintos tipos. A través de la comparación con otros sitios similares intentaremos acercarnos a una tipología de los lugares con función ritual en la Edad del Hierro.

Palabras Clave: Santuarios rupestres, Pilas, Edad del Hierro, Castros, Santa Mariña de Maside, Galicia.

\section{AS PÍAS DO CASTRO DE SANTA MARIÑA DE MASIDE (OURENSE): CARA A UNA TIPOLOXÍA DOS LUGARES CON FUNCIÓN RITUAL NA IDADE DO FERRO DO NW DA PENÍNSULA IBÉRICA}

RESUMO

Neste artigo pretendemos deternos con certo detalle nas pías que aparecen en contextos de castros de cara a avaliar a súa posible función relixiosa. O noso interese centrarase no castro de Santa Mariña de Maside (Ourense), onde existen varias rochas con pías rectangulares e rebaixes de distintos tipos. A través da comparación con outros sitios similares intentaremos achegarnos a una tipoloxía dos lugares con función ritual na Idade do Ferro.

Palabras clave: Santuarios rupestres, Pías, Idade do Ferro, Castros, Santa Mariña de Maside, Galicia.

\section{SANTA MARIÑA DE MASIDE (OURENSE)HILLFORT ROCK BASINS: TOWARDS A TYPOLOGY OF PLACES WITH RITUAL FUNCTIONS FROM THE IRON AGE IN THE NORTH-WEST OF THE IBERIAN PENINSULA}

\section{Abstract}

In this article we pretend to review in detail the rock basins that appear in hillfort contexts. Our purpose will be to evaluate their possible religious function. Our interest will be focused on the Santa de Mariña de Masidehillfort (Ourense) where several rocks with rectangular holes and different types of shapes are found. We will try to find a typology on Iron Age places with a religious ritual function throughout the comparison with other similar sites.

KEY WORDS: Rocky sanctuaries, Rock basins, Iron Age, hillforts, Santa Mariña de Maside, Galicia. 
Recibido/Received: 07/07/2013

Aceptado/Accepted: 26/08/2013

\section{LA “DESLOCALIZACIÓN” DE LOS POBLADORES DE LOS CASTROS}

$\mathrm{U}$

no de los cambios más relevantes que se ha producido en el estudio de la Edad del Hierro del NW peninsular en los últimos años ha consistido en aprender a ver a los "castrexos" fuera de sus hábitats. Gracias a los trabajos de seguimiento del impacto arqueológico de grandes obras públicas se han podido identificar un buen número de nuevos tipos arqueológicos y, en particular, algunos relacionados con las actividades de los habitantes de los castros de puertas afuera de sus lugares de residencia. Así se han reconocido áreas de cultivo anejas a las fortificaciones castreñas ${ }^{1}$ y zonas de actividad minera ${ }^{2}$ anterior a la presencia romana ${ }^{3}$; también se han encontrado indicios recurrentes de actividad comercial, no sólo en castros costeros, desde el siglo VI a.C.4; y por último se han identificado lugares de probable función ritual tanto en el interior como en el exterior de los castros (ver más abajo).

1 César Parcero-Oubiña, La Arqueología en la Gasificación de Galicia 7: Hacia una Arqueología Agraria de la Cultura Castreña, Santiago de Compostela, Grupo de Investigación de Arqueología del Paisaje, Universidad de Santiago de Compostela, 1998 (Traballos de Arqueoloxía da Paisaxe, TAPA, 9).

2 En Antonio Martínez Cortizas, Eduardo García-Rodeja, Xabier Pontevedra Pombal, Juan Carlos Nóvoa Muñoz, Dominik Weiss y Andriy Cheburkin, "Atmospheric Pb deposition in Spain during the last 4600 years recorded by two ombrotrophic peat bogs and implications for the use of peat as archive", Science of the Total Environment, 292 (2002), págs. 33-44: y en Malin E. Kylander, Dominik J. Weiss, Antonio Martínez Cortizas, Baruch Spiro, R. García-Sánchez y Barry COLES, "Refining the pre-industrial atmospheric $\mathrm{Pb}$ isotope evolution curve in Europe using and 8000 year old peat core from NW Spain", Earth and Planetary Science Letters, 240 (2005), págs. 467-485, se puede leer sobre el impacto de la minería y la metalurgia en el NW durante la Edad del Hierro. A través del análisis de la acumulación de metales y su composición isotópica concluyen que en el periodo comprendido entre el 1050-580 a. C. hay una fase de aumento de contaminación, y por tanto de actividad minero-metalúrgica respecto a momentos anteriores, que a su vez se incrementa sustancialmente en el periodo siguiente que va de del 580 a. C. al 250 a. C.

3 Roberto Aboal-Fernández, Xurxo Miguel Ayán Vila y María Pilar Prieto Martínez "El área arqueológica de O Peto (Vedra, A Coruña, Galicia): ¿posible explotación minerometalúrgica prerromana?", Era-Arqueologia, 5 (2003), págs. 104-123.

4 Alfredo González-Ruibal, Rafael María Rodríguez Martínez y Xurxo Miguel Ayán VILA,"Buscando a los Púnicos en el Noroeste”, Mainake, 32-1 (2010), págs. 577-600. 
Aunque en la actualidad cada vez se impone más la denominación "Edad del Hierro", desde los años 80 se utilizó para designar este periodo y cultura el término "castrexo", que tiene el efecto de ocultar toda esa amplia y heterogénea actividad. Además, profundizando un poco, destacan otros aspectos cuestionables de esta denominación. Por una parte, tiene como consecuencia “prehistorizar" la Edad del Hierro del NW peninsular al equipararla a cualquier otra cultura prehistórica denominada a partir de un fósil director arqueológico distintivo. Por otro lado, subraya las diferencias de esta cultura con respecto a las demás culturas de la Edad del Hierro peninsulares y europeas conocidas mediante etnónimos de distinto rango. Estas "prehistorización” y "desetnización” de la Edad del Hierro son la consecuencia del triunfo de una arqueología que se buscaba como científica reaccionando contra los modelos histórico-culturales y haciendo tabla rasa de la cuestión étnica y del estudio de la estructura social de la Edad del Hierro ${ }^{5}$ Pero ese estado de cosas se ha replanteado con posterioridad ${ }^{6}$ no sin suscitar reacciones en defensa del status quo ${ }^{7}$.

No pretendemos entrar en este debate, que conforma el escenario historiográfico donde nos situamos, sino que intentaremos contribuir a una de las líneas de deslocalización enunciadas. En concreto la que trata de identificar la huella de la acción ritual de las poblaciones de la Edad del Hierro más allá de sus murallas partiendo de la prospección intensiva desarrollada en el denominado Castro de Santa Mariña (Maside, Ourense).

Comenzaremos situando el estado de los estudios sobre espacios rituales en la Edad del Hierro y sugiriendo la utilidad del uso de tipologías para perfeccionar su estudio (apartado 2). Seguidamente abordaremos la descripción del conjunto arqueológico (apartado 3) que ubicaremos en la clasificación propuesta y en el contexto del paisaje arqueológico local, lo que dará pie a una interpretación de conjunto (apartado 4). Concluiremos que el estudio sobre estas cuestiones debe avanzar al mismo tiempo en sentido general y mediante estudios pormenorizados de casos concretos.

\footnotetext{
5 Francisco Javier González García, Los pueblos de la Galicia Céltica, Madrid, Akal, 2007, págs. 72-9.

6 María Dolores Férnández Posse y Francisco J. Sánchez Palencia "Las comunidades campesinas en la Cultura Castreña", Trabajos de Prehistoria, 55-2 (1998), págs. 127-150. Inés SASTRE Prats, Las formaciones sociales rurales de la Asturia Prerromana, Ediciones Clásicas, Madrid, 2001. César Parcero-Oubiña, La construcción del Paisaje Social en la Edad del Hierro del Noroeste Ibérico, Ortigueira, Fundación Ortegalia, 2002. Francisco Javier GonZález García, Los pueblos de..., Alfredo González-Ruibal, Galaicos. Poder y comunidad en el Noroeste de la Península Ibérica (1200 a. C. - 50 d. C.), 2 vols, A Coruña, Brigantium, 2006-2007.

7 José Carlos Bermejo Barrera, Sociedade e Relixión na Galicia Antigua, Santiago, Lóstrego. 2008, comentado en Marco V. García Quintela, "Sociedad y Religión en la Galicia Antigua: una historia del tiempo abolido", Gerión, 27 vol. 2 (2009), págs. 79-105; y Francisco Calo Lourido, Os celtas: unha (re)visión dende Galicia, Vigo, Edicións Xerais de Galicia, 2010.
} 
LAS PILAS DEL CASTRO DE SANTA MARIÑA DE MASIDE (OURENSE):

HACIA UNA TIPOLOGÍA DE LOS LUGARES CON FUNCIÓN RITUAL EN

LA EDAD DEL HIERRO DEL NW DE LA PENÍNSULA IBÉRICA

\section{Historia Y TIPOLOGías DE LA HUELla ARQUEOLÓGICA DE LA ACCióN RITUAL EN LA EDAD DEL HiERRO DEL NW PENINSUlaR.}

Desde hace aproximadamente una década se interpretan determinados yacimientos del NW peninsular en los que aparecen pilas rupestres, acompañadas o no de otros elementos antrópicos, como lugares usados con finalidad religiosa por los habitantes de los castros ${ }^{8}$. Estos lugares habían llamado la atención de los estudiosos de la arqueología castreña en los años cincuenta ${ }^{9}$. Sin embargo con posterioridad su estudio se abandonó pues muchos investigadores lo contemplaron, y todavía lo contemplan, con desconfianza debido a innegables excesos interpretativos de aquellos años que tuvieron, como daño colateral, que estas entidades arqueológicas en cuestión se relegaran al olvido. Una excepción es A. Rodríguez Colmenero ${ }^{10}$, que en su libro Galicia meridional romana cataloga varios de estos yacimientos arqueológicos.

Este panorama está cambiando a partir de trabajos que, siguiendo inquietudes diferentes, reavivan el interés por este tipo de lugares en el NW peninsular. Así se ha partido de la lógica del catálogo que impuso, seguidamente, la necesidad de interpretar esta clase de ítems arqueológicos ${ }^{11}$. Por otra parte se ha constatado que las pilas forman parte de los paisajes simbólicos de las poblaciones campesinas y, en este sentido, siempre han sido estructuras dotadas de sentido ${ }^{12}$, con independencia de la intención de sus constructores en el pasado ${ }^{13}$. También se han identificado estaciones de arte rupestre de la Edad del Hierro que incluyen

\footnotetext{
8 Manuel Santos Estévez, "Los espacios del arte: el diseño del panel y la articulación del paisaje en el arte rupestre gallego", Trabajos de Prehistoria, 55, núm. 2 (1998), págs. 73-88.

9 Florentino LóPez Cuevillas, "Sobre la mitología y las costumbres relativas a tres pilas megalíticas del Ribeiro de Avia", Cuadernos de Estudios Gallegos, 9 (1954), págs. 181-191. Florentino López Cuevillas y Joaquín Lorenzo Fernández, "Cuatro peñas con pilas, del sur de Galicia", Cuadernos de Estudios Gallegos, 7 (1952), págs. 5-54. Luis Monteagudo García, "La religiosidad gallaica: estela funeraria romana de Mazarelas (Oza dos Ríos, A Coruña), cultos astrales, priscilianismo y outeiros", Anuario brigantino, 19 (1996), págs. 11-118.

${ }^{10}$ Antonio Rodríguez Colmenero, Galicia meridional romana, Bilbao, Ed. Universidad de Deusto, 1977.

${ }^{11}$ Israel Barandela Rivero y José Manuel Lorenzo Rodríguez, Petroglifos de Ourense, Reflexións a un primeiroreconto da arte rupestre prehistórica na provincia de Ourense, Ourense, Diputación provincial de Ourense, 2004. Israel Barandela Rivero, Ladislao Castro Pérez, José Manuel LoREnzo Rodríguez y Rafael Otero, "Notas sobre los santuarios rupestres de la Gallaecia”, Minius, 13 (2005), págs. 47-68.

${ }^{12}$ Manuel Santos Estévez, "Los espacios del arte...”, págs. 73-88.

13 Álvaro Arizaga Castro y Xurxo M. Ayán Vila, "Etnoarqueología del paisaje castreño: la segunda vida de los castros", en F.J. González García (ed.), Los pueblos de la Galicia Céltica, Akal, Madrid, 2007, págs. 445-531, en especial 473-479.
} 
este tipo de formas arqueológicas ${ }^{14}$, o se han integrado en estudios generales sobre la Edad del Hierro regional ${ }^{15}$. Paralelamente, en el $\mathrm{N}$ de Portugal nunca se había perdido el interés por estas manifestaciones destacando, últimamente, el trabajo sistemático sobre estos yacimientos que lleva a cabo M.J.C. Santos ${ }^{16}$.

Los santuarios rupestres más emblemáticos están en el NE portugués destacando lugares como Panoias (Vale de Nogueira, Vila Real) con su combinación de epigrafía y rocas monumentalizadas, Pías dos Mouros (Argeriz, Valpaços) con dos escaleras en paralelo que enmarcan dos pilas rectangulares, o Castelo de Mau Vizinho ${ }^{17}$ (Chaves) con unas estructuras más simples como agujeros de poste, pilas y cazoletas. En Galicia podemos señalar ejemplos concentrados en la provincia de Ourense, como el de Laias, actualmente destruido, que presentaba una serie de pilas cuadradas y circulares con canales, escaleras y una estructura rectangular con un pilar central ${ }^{18}$, o el de Armea en Santa Mariña de Augas Santas (Allariz), recientemente descubierto, con una pila rectangular, varios canales y dos filas de escaleras dispuestas E-W que recuerdan las Pías dos Mouros de Argeriz.

Durante mucho tiempo la gran mayoría de estas estructuras se fecharon en el periodo romano ${ }^{19}$ pero en la actualidad gran parte de los investigadores de-

\footnotetext{
${ }^{14}$ Marco Virgilio García Quintela y Manuel Santos Estévez, Santuarios de la Galicia Céltica, Madrid, Abada, 2008, págs. 134-42. Manuel Santos Estévez, Petroglifos y paisaje social en la prehistoria reciente del Noroeste de la Península Ibérica, Santiago de Compostela, Laboratorio de Arqueoloxía-Instituto de Estudios Gallegos "Padre Sarmiento", CSIC, 2008 (Traballos de Arqueoloxía e Patrimonio, TAPA, 38).

${ }^{15}$ Alfredo GonZález-Ruibal, Galaicos. Poder y comunidad en el..., vol. 2, págs. 560-565.

${ }^{16}$ Maria João Correia SAntos, "Santuarios rupestres no occidente da Hispania indo-europeia. Ensaio de tipologia e clasifiçao", Palaeohispanica, 10 (2010), págs. 147-172. Maria João CoRREIA SAnTos, "Inscripciones rupestres y espacios sagrados del norte de Portugal: nuevos datos y contextualización", en J. Alberto Arenas-Esteban (ed.), Celtic Religion across Space and Time. IX Workshop F.E.R.C.AN. Fontes Epigraphici Religionum celicarum Antiquarum, Toledo, Junta de Comunidades Castilla-La Mancha, 2010. Maria João Correia SAntos, "O Cabeço de Fráguas e a concepçâo de espaço sagrado na Hispania indo-europeia”, Iberografias, 6 (2010), págs. 131-141.

${ }^{17}$ Conviene señalar que según Maria João Correia SAntos, "La arqueología, lo imaginario y lo real. El santuario rupestre de Mogueira (Sâo Martinho de Mouros, Portugal)", Madrider Mitteilungen (2012), págs. 455-96, este sitio podría tener una cronología medieval, al igual que Mogueira (Resende) cuya excavación permitió refutar la cronología castreña y romana preexistente y comprobar que el santuario rupestre se trataba de una fortificación medieval. Además se verificó que sí existió un santuario, pero que éste no se ubicaba en el lugar que se pensaba inicialmente.

${ }^{18}$ Luis Francisco López GonzÁLez y Yolanda Álvarez GonZÁLez, "La secuencia cultural del asentamiento de Laias: evolución espacial y funcional del poblado", Proto-historia da Península Ibérica. ADECAP (2001), págs. 523-530.

${ }^{19}$ Antonio Rodríguez Colmenero, "Corpus-Catálogo de inscripciones rupestres de época romana del cuadrante Noroeste de la Península Ibérica", en Antonio Rodríguez Colmenero y Lido Gasperini (eds.), Saxa Scripta (Inscripciones en Roca). Actas del Simposio Internacional Ibero-Itálico sobre Epigrafia Rupestre, Santiago de Compostela y Norte de Portugal, 1992, La Coruña, Edicions do Castro, 1995 (Anejos de Larouco, 2).
} 
fienden su origen protohistórico ${ }^{20}$. Por ejemplo, el estudio pormenorizado de Panoias ha permitido reconocer dos fases, una prerromana, con pilas circulares, y otra plenamente romana, con las pilas cuadradas y rectangulares y las inscripciones $^{21}$. Los casos en proceso de estudio de PedraFurada ${ }^{22}$ (Coirós, A Coruña) y de Santa Mariña de Augasantas (Allariz, Ourense) coinciden en mostrar una fase prerromana y otra de reutilización o de continuidad de uso durante el período romano. Con otro tipo de registro, el santuario de Berobreo en cabo Home en la península del Morrazo (Pontevedra) muestra la sacralización de un punto topográfico liminal que se revitaliza durante el período romano con el culto a una divinidad prerromana ${ }^{23}$.

Estas apreciaciones no deben ocultar que la dificultad mayor está en definir los lugares a los que atribuir una función religiosa y, todavía más, precisar el período de vigencia de tal función. A estas dificultades se añade la definición de tipología de las pilas consideradas en estos estudios. Una definición estrictamente formal a partir de la consideración de medidas etc. parece insuficiente porque la variedad es muy grande y los casos conocidos deben considerarse como una suerte de "avance pretipológico" que en algún momento tendrá que convertirse en una tipología digna de tal nombre. Para esquivar esta situación de provisionalidad se pueden utilizar dos criterios complementarios para identificar pilas de posible función simbólica: por un lado un examen detenido que permita identificar sin ambigüedades su origen antrópico, para este examen de las pilas deberíamos utilizar indicadores como la presencia de ángulos marcados; la regularidad de su forma y su profundidad comparada con otras manifestaciones de erosión natural; la presencia de canales, rebajes, bordes en la misma roca o rocas cercanas etc.; por otro lado es importante el propio contexto arqueológico o topográfico, serán pilas no funcionales para las actividades cotidianas aquellas con accesos difíciles, junto a barrancos, más o menos alejadas de las estructuras de

\footnotetext{
${ }^{20}$ Gonzalo Ruiz Zapatero y Jesús R. Álvarez-Sanchís, "Ulaca la Pompeya Vettona”, Revista de Arqueología, 216 (1999), págs. 36-47. Marco Virgilio García Quintela y Manuel Santos EsTÉveZ, Santuarios de la Galicia..., Maria João Correia Santos, "Santuarios rupestres...", págs. 147-172. Maria João CoRreia SANTOS, "Inscripciones rupestres...”, pág. 150.

${ }^{21}$ Antonio Rodríguez Colmenero, O santuario rupestre Galacio-Romano de Panoias (Vila Real, Portugal). Novas achegas para a sua reinterpretaçao global, Vila Real, Breogán, 1999, págs. 105106. Maria João Correia SAntos, "Santuarios rupestres...", págs. 147-172 ambos actualizan de formas diversas el trabajo que marcó un hito en la interpretación Geza ALFöLDI,"Die mysterien von Panoias (Vila Real, Portugal)", Madrider Mitteilungen, 38 (1997), págs. 176-246.

${ }^{22}$ Se puede ampliar la información en el siguiente enlace: http://www.manuelgago.org/blog/index. php/2011/05/26/o-misterio-da-moura-de-coiros/

${ }^{23}$ Michael KocH, "El Santuario dedidado a Berobreo en el Monte do Facho (Cangas, Galicia)", Palaeohispánica, 5 (2005), págs. 823-836. Thomas Schattner, José Suárez Otero y Michael Koch, "Monte do Facho (O Hío, prov. Pontevedra) 2004: informe sobre las excavaciones en el Santuario de Berobreo", Palaeohispánica, 6 (2006), págs. 183-223.
} 
habitación y que forman parte de otros trabajos no funcionales (aparentemente) como rebajes, escalones tallados en la roca que no parecen comunicar nada, etc.

A partir de estos elementos consideramos que en lo referente a la Edad del Hierro partimos de una doble premisa cultural y comparativa que establece la oportunidad de buscar un referente material de los hechos que constituyen tal premisa.

La premisa cultural es que las lenguas habladas en la Edad del Hierro del NW eran indoeuropeas, aunque los especialistas discuten las relaciones entre los testimonios de lengua celta y los testimonios de "lusitano". De esta constatación deriva la legitimidad de buscar y, según los casos, postular la vigencia de los términos del vocabulario religioso compartidos en diferentes lenguas, y sobre todo en las más directamente relacionadas con esta zona. Un ejemplo es de interés particular en nuestro argumento.

De la raíz indoeuropea *tem- derivan el griego temenos, espacio sagrado y acotado dedicado a los dioses ${ }^{24}$, el latín templum, espacio acotado por el augur para emprender una acción legitimada por los dioses ${ }^{25}$, o el celta nemeton, espacio acotado donde se unen el cielo y la tierra ${ }^{26}$. También se ha propuesto que Temair, el nombre antiguo de la capital espiritual de la Irlanda pagana y de otra veintena de lugares, deriva de esta raíz ${ }^{27}$.

Pues bien, nemeton es un término relativamente bien atestiguado en el NW peninsular. Lo conocemos a través de dos epígrafes, uno inscrito en una roca situada en un espacio abierto en la ladera N del gran castro de Sanfins en Paços de Ferreira ${ }^{28}$ otro es una inscripción encontrada en Mieres, Asturias ${ }^{29}$. También forma parte del topónimo compuesto "Nemetobriga" atestiguado por Tolomeo en la actual provincia de Ourense ${ }^{30}$, y también como topónimo a través de la

\footnotetext{
${ }^{24}$ John G. Pedley, Sanctuaries and the sacred in the ancient Greek world / New York, Cambridge, University Press, 2005, págs. 57-62.

25 Jerzy LiNDERSKI, “The Augural Law”, ANRW, II/16/3 (1986), págs. 2146-2312.

${ }^{26}$ Pierre-Yves Lambert, "Gauloisnemeton et atośdeuogdonion:deuxnoms de l'espacesacré", en X. Dupré et al., Saturnia Tellus. Definizioni dello spazio consacrato in ambiente etrusco, italico, fenicio-punico, iberico e céltico. Actas del congreso internacional (10-12 noviembre 2004 - Roma), Roma, Consiglio Nazionale delle Ricerche, 2008, págs. 133-149.

${ }^{27}$ DónallMac Grolla EasPaIG, "Ireland's heritage of geographical names", Wiener Schriftenzur Geographie und Kartographie, 18 (2009), págs.79-85.

${ }^{28}$ Juan Carlos Búa Carballo, "Hipótesis para algunas inscripciones rupestres del Occidente Peninsular", en F. Villar y F. Beltrán (eds.), Pueblos, Lenguas y Escrituras en la Hispania Prerromana, Salamanca, Ed. Universidad de Salamanca, 1999, págs. 314-317.

${ }^{29}$ Francisco Diego Santos, Epigrafía romana de Asturias, Oviedo, Ed. Universidad de Salamanca, 1984, págs. 49-51.

${ }^{30}$ Juan Luis García Alonso, La Península Ibérica en la Geografía de Claudio Ptolomeo. VitoriaGasteiz, Ed. Universidad del País Vasco, 2003, págs. 229-31.
} 
forma medieval derivada nemitus en la actual Betanzos: "territorio Nemitus inter duosfluvios, Menendi et Barosa, subtus Monte Castro"31, refiriéndose a los actuales ríos Mendo y Mandeo que confluyen bajo el casco urbano de la Betanzos medieval y a un tipo de enclave de frecuente función religiosa en el mundo céltico. Otra cosa es, como decíamos, identificar el (o los) posible(s) referente(s) material(es) del término, pues de estas constataciones no cabe inferir un camino seguro.

En efecto, el avance de los estudios ha puesto de relieve la diversidad de los espacios rituales en diferentes culturas de tradición indoeuropea tanto en el plano de los términos usados ${ }^{32}$, como en el de las realidades materiales (ver los artículos sobre Italia reunidos en Cahiers Glotz, 8 (1997), págs. 51-222; las síntesis regionales para la Galia reunidas por Arcelin y Brunaux ${ }^{33}$; la presentación del proyecto CIRCE en la Revue de l'histoire des religions, 4 (2010), págs. 703-719; y, centrado en el mundo extra-clásico X. Dupré et al..$^{34}$ ). A ellos se añaden las descripciones literarias antiguas acerca de santuarios donde no hay nada construido (por ejemplo, en Grecia, Jenofonte, Anábasis V, 3.7-13; en Roma: Tito Livio I, 10.5-7; entre los germanos: Tácito, Germania 40; entre los celtas de Provenza: Lucano, Farsalia III; 398-429) ¿cuántas entidades de esta naturaleza pudieron existir en los más diversos lugares y épocas y nunca podremos identificar?

Somos conscientes, por lo tanto, de que atribuir un sentido sagrado a un lugar es muy difícil ya que tal sentido puede existir con independencia de que se produzca una monumentalización o, simplemente, alguna alteración del espacio natural que pueda incluso ser tan discreta que sea imposible identificarla, y aún más difícil es saber si tal lugar tenía una finalidad simbólica. Además, la escasez de excavaciones en estos entornos o, de haberlas, la ausencia o pobreza del registro arqueológico asociado hacen todavía más dificultoso aseverar la cronología y funcionalidad de estos lugares cuando no hay epigrafía asociada (así las excavaciones en los santuarios de Berobreo o en la croa de Las han proporcionado

\footnotetext{
${ }^{31}$ Pilar Loscertales de G. De Valdeavellano, Tumbos del Monasterio de Sobrado de los Monjes, Madrid, Ed. Archivo Histórico Nacional, 1976, vol. I, pág. 173.

32 John SCHEID, “Commentidentifier un lieu de culte?", Cahiers du Centre Gustave Glotz, 8 (1997), págs. 51-59. Fay Glinister, "What is a sanctuary?", Cahiers du Centre Gustave Glotz, 8 (1997), págs. 61-80. Pierre BrULÉ, "Le sanctuaireest un sanctuaire", Bandue, 4 (2010), págs. 25-65.

${ }^{33}$ Patrice ARCELIN y Jean-Louis BRUnAux, "Un état des questions sur les sanctuaires et les pratiquescultuelles de la Gaule Celtique”, Gallia, 6 (2003), págs.1-268.

${ }^{34}$ Xavier Dupré Raventos, Sergio Ribichini y Stephano Verger, Saturnia Tellus. Definizioni dello spazio consacrato in ambiente etrusco, italico, fenicio-punico, iberico e céltico. Actas del congreso internacional (10-12 noviembre 2004-Roma), Roma, Consiglio Nazionale delle Ricerche, 2008, págs. 12-26.
} 
esos epígrafes, pero la excavación de A Ferradura ${ }^{35}$ ha resultado estéril (están en curso trabajos en Pedra Furada y Armea).

La consecuencia de todo esto es que no existe un modelo establecido de santuario (o santuarios) y que no están definidos los elementos formales que los caracterizan y con qué tipo de prácticas se asocian (es importante la revisión crítica de Alfayé Villa ${ }^{36}$ para el valle del Ebro y la Meseta). En el área NW lo escaso y elusivo de las huellas arqueológicas de la función religiosa son una constante. Sin embargo también existe cierta inercia historiográfica que tiene el efecto de invisibilizar cualquier clase de resto arqueológico que se aleje de los tipos establecidos y cuya interpretación sea problemática. Sin embargo, esta situación no ha impedido que en los últimos años se hayan señalado cierta cantidad de posibles espacios sagrados que presentan rasgos variados.

García Quintela y Santos Estévez ${ }^{37}$ partieron de la observación de cuatro casos complejos: As Canles (Pontevedra), Corme (A Coruña), Pedrafita (Lugo) y A Ferradura (Ourense) (de este último hablaremos más abajo por encontrarse en el entorno de Santa Mariña de Maside). Su estudio llevó a identificar una serie de rasgos compartidos que conformaban un modelo. Además, existen dos propuestas de clasificación coincidentes en analizar las formas presentes en la roca y proponen, a partir de ahí, una cronología relativa. Por un lado Barandela Rivero et al. ${ }^{38}$ parten de la definición de santuario propuesta por F. Marco Simón ${ }^{39}$ que aplican sobre una muestra de dieciséis ejemplos divididos en dos grupos. El primero y más sencillo, estaría formado por santuarios de profunda huella prehistórica, compuestos por pilas y cazoletas, e incluyen entre otros los ejemplos de Outeiro Redondo (Montecelo, Baltar), Cruceiro de Cornoces situado en las inmediaciones del castro de Monte da Eirexa (Cornoces, Amoeiro) y O Pedrón (Celanova). El segundo grupo estaría compuesto por los santuarios rurales sin epígrafes votivos que, sin embargo, presentan evidentes vestigios de monumen-

\footnotetext{
${ }_{35}$ Manuel Santos Estévez y Yolanda Seoane-Veiga, "Escavación no contorno dun petroglifo en A Ferradura". Arkeos: Arte Rupestre, Pre-historia, Patrimonio, 5 (2004), págs. 37-55. Yolanda Seoane Veiga, María Pilar-Prieto Martínez y Cecilia Dal Zovo, "Bell beaker findingsin rock art contexts" en María Pilar Prieto Martínez y Laure Salanova (coords.), Current researche son Bell Beakers (Proceedings of the 15 ${ }^{\text {th }}$ International Bell Beaker Conference: From Atlanticto Ural. $5^{\text {th }} 9^{\text {th }}$ May 2011, Poio, Pontevedra, Galicia, Spain), Santiago de Compostela, Galician Archaeo Pots, 2013, págs. 31-40.

${ }^{36}$ Silvia Alfayé Villa, Santuarios y rituales en la Hispania Céltica, Oxford, Archaeopress, 2009 (BAR International Series, 1963).

${ }^{37}$ Marco Virgilio García Quintela y Manuel Santos Estévez, Santuarios de la Galicia...

${ }^{38}$ Israel Barandela Rivero, Ladislao Castro Pérez, José Manuel Lorenzo Rodríguez y Rafael OTERo "Notas sobre los santuarios...", pág. 49

${ }^{39}$ Francisco Marco Simón, "Romanización y aculturación religiosa: los santuarios rurales", en Susana Reboreda y Pedro López Barja (eds.), A cidade e o mondo: Romanización e cambio social, Xinzo de Limia, Concello, 1996, págs. 81-100.
} 
talidad (pilas claramente antrópicas, escaleras, canales etc), como pueden ser Castro de San Vicenzo (Avión); Santomé (Ourense); Outeiro do Castro (Valverde, Allariz), Armea (Santa Mariña de Augas Santas, Allariz), Santa Mariña de

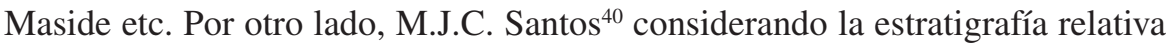
de las formas que tienen las pilas propone su tipificación morfológico-temporal. La primera fase se caracteriza por el uso de pilas naturales asociadas a contextos indígenas no romanizados. En la segunda las pilas anteriores se mezclan con otras artificiales u otras estructuras. Finalmente aparecen las pilas ortogonales y la epigrafía en un contexto ya plenamente romano.

Sobre estas propuestas es preciso comentar que cuando sólo hay pilas circulares sin elementos claramente antrópicos asociados como pueden ser grabados, rebajes o canales, puede suceder que se consideren naturales, pues de hecho es imposible trazar los límites con alguna clase de criterio formal. Pero si bien es cierto que el origen de la pila puede ser natural ${ }^{41}$ también lo es que más tarde pudo ser utilizada y aprovechada para fines rituales

Reconociendo el interés de las aportaciones indicadas, proponemos una tipología provisional de evidencias en el paisaje y en el registro arqueológico que podrían ser interpretadas como restos de los lugares usados por los habitantes de los castros con fines rituales:

1. Arte rupestre de la Edad del Hierro. Entran en esta categoría las estaciones o petroglifos que por distintas razones pueden considerarse propias de esta época (Vacariza en Santa Mariña de Augas Santas ${ }^{42}$, Fentáns en Campo Lameiro $^{43}$, y las estaciones y petroglifos anteriores con indicios de reutilización

\footnotetext{
${ }^{40}$ Maria João Correia SANTos, "Santuarios rupestres...”, págs. 147-172.

${ }^{41}$ Las gnammas (también conocidas como piletas rupestres) son pequeñas cavidades producidas por erosión que, normalmente, se presentan en rocas graníticas. Su diámetro puede variar de centímetros a metros y son frecuentemente más anchas que profundas. Las formas son típicamente redondas o elíptica, aunque también existen formas irregulares. Su origen es debido a procesos erosivos físico- químicos causados por el estancamiento del agua que se acumula en las irregularidades de la roca. David Domínguez-Villar, Carlos Arteaga, Rosario García-Giménez, Eric Smith y Javier de Pedraza Gilsanz, "Diurnal and seasonal water variations of temperatura, $\mathrm{pH}$, redox potencial and conductivity in gnammas (weathering pits): Implications for Chemicals Weathering", Catena, 72 (2008), págs. 37-48. David Domínguez-Villar, Laura Razola, Rosa Carrasco, C. Jennings y Javier de Pedraza Gilsanz, "Weathering phases recorded by gnammas developed since last glaciation at Serra da Estrela, Portugal", Quaternary Research, 72 (2009), págs. 218-228. ${ }^{42}$ Marco Virgilio García Quintela y Yolanda Seoane-Veiga, "La larga vida de dos rocas ourensanas", Archivo Español de Arqueología, 84 (2011), págs. 243-266

${ }^{43}$ César Parcero-Oubiña, Felipe Criado-Boado y Manuel Santos Estévez, "Rewriting landscape: incorporating sacred landscapes into cultural traditions", World Archaeology, 30-1 (1998), págs. 159-176. Marco Virgilio García Quintela y Manuel Santos Estévez, Santuarios de la Galicia...
} 
durante la Edad del Hierro mediante la inserción de grabados característicos del Estilo Esquemático Atlántico definido por M. Santos Estévez ${ }^{44}$. También debemos incluir en esta categoría aquellos petroglifos que según Santos Estévez ${ }^{45}$ pertenecen a la última fase del Estilo Atlántico. Se trata de escenas de caza, monta, laberintos y paletas realizados en la primera Edad del Hierro, más concretamente entre los siglos IX-VII y V-IV a. C.

2. Grandes rocas monumentalizadas. Son afloramientos rocosos o grandes batolitos con trabajos como escaleras, canales, pilas o indicios de erosión causada por termoclastia, que pueden implicar un uso intencional del fuego. El resultado es construir una escenografía a partir de la roca con trabajos que no son grabados, o arte rupestre propiamente dicho. Los ejemplos portugueses citados (Panoias, Pías dos Mouros) son muy claros, pero hay otros también claros y distantes como Pedra Fita en Lugo ${ }^{46}$, o PedraFurada en Coirós ${ }^{47}$. En una posición geográfica intermedia están los casos de la provincia de Ourense: el santuario vinculado con el castro de Armea (Allariz) en curso de estudio y el caso del castro de San Vicenzo (Avión), que nos ocupará más abajo.

3. Rocas con pilas. En ocasiones las pilas aparecen aisladas de otras estructuras arqueológicas en el contexto inmediato, siendo por tanto el único elemento a considerar. Distinguimos esta categoría de la anterior por el tamaño relativo de las rocas trabajadas, más pequeñas y/o aisladas. Es posible que algunas tuviesen funciones utilitarias como lagares para el vino ${ }^{48}$ (información en la red en servino.net y el blog "Capítulo 0" buscando las palabras "lagar" o "lagareta”) pero otras como A Pena Escrita ${ }^{49}$ y el Pedrón de Celanova ${ }^{50}$ tuvieron una clara función religiosa. Es necesario por lo tanto un estudio caso por caso pues operamos sobre una muestra de contornos mal definidos.

\footnotetext{
${ }^{44}$ Manuel Santos Estévez, Petroglifos y paisaje social..., págs. 123-87.

${ }^{45}$ Manuel Santos Estévez, "Sobre la cronología del Arte Rupestre Atlántico en Galicia", Arqueoweb, 7/2 (2005) [en línea], disponible en < http://www.ucm.es/info/arqueoweb/pdf/7-2/santos. pdf $>$.

${ }^{46}$ Marco Virgilio García Quintela y Manuel Santos Estévez, Santuarios de la Galicia..., págs. 134-136.

${ }^{47}$ Fernando Alonso Romero, "La figura de mujer del petroglifo da Pena Furada (Figueiras, Santa Mariña de Lesa, Coirós, A Coruña)", Anuario Brigantino, 27 (2004), págs. 161-178. Antón FeRNÁNdez Malde, "Petroglifos da Pena Furada (Figueiras, Coirós)", Anuario Brigantino, 16 (1993), págs. 15-24.

${ }^{48}$ Estanislado Fernández De La Cigoña, O Aceite en Galicia. Guía das Lagaretas CastrexoRomanas, Medievais e Modernas, Vigo, Asociación Galega para a Cultura e a Ecoloxía e Instituto Galego de Estudos Mariños, 2003 (Col. Etnografía Galega).

${ }^{49}$ Maria João CoRreia SANTOs, "Inscripciones rupestres y espacios...", págs. 193-5.

${ }^{50}$ Marco Virgilio García Quintela y Yolanda Seonne-Veiga, "La larga vida de...”, págs. 251253 y $258-61$.
} 
4. Arquitectura ambigua. Con esta expresión designamos rocas naturales o trabajadas de forma discreta, como intentando pasar desapercibidas, lo que en ocasiones permite dudar sobre la existencia de tales acciones. Sin embargo, los lugares dónde se sitúan esas rocas están fuertemente antropizados, y las rocas mismas pueden formar parte de alineaciones astronómicas o tener una función simbólica mantenida como destino de romerías o sede de tradiciones folklóricas. Las rocas que conforman el "Outeiro dos Pendóns" ubicado en el castro de Armea reúnen estas condiciones, la aglomeración rocosa conocida como "O Raposo" en el área de grabados rupestres de Ferradura es otro ejemplo ${ }^{51}$.

5. Saunas galaicas con o sin pedrasformosas. Sabemos que su función religiosa o simbólica es discutida y no podemos entrar en esta cuestión ${ }^{52}$. Digamos simplemente que de la misma forma que estamos haciendo un elenco de espacios de uso ritual podríamos, con otra perspectiva, hacer una tipología de los usos de la roca en cuanto materia prima de la acción simbólica en la Edad del Hierro ${ }^{53}$ y de esta forma las saunas encontrarían de forma natural un lugar en la tipología de estructuras de uso simbólico que proponemos.

6. Acrópolis de los castros. Con rasgos formales, fechas y localizaciones diversas los casos de Chao Samartín ${ }^{54}$, Castro Grande de Neixón ${ }^{55}$ y San Cibrán de Las ${ }^{56}$, apuntan con claridad en esta dirección. En todos ellos hay formas peculiares de tratar el contexto rocoso en relación con la propia estructura de la acrópolis.

\footnotetext{
${ }^{51}$ Véase Marco V. García Quintela, Yolanda Seonne-Veiga, "Entre Naturaleza y Cultura: Arquitectura ambigua en la Edad del Hierro del NO peninsular", [en prensa].

52 Armando Coelho da Silva, Pedra formosa: arqueologia experimental, Vila Nova de Famalicão, Câmara Municipal de Vila Nova de Famalicão; Museu Nacional de Arqueologia, 2007.Ángel VILLA VALDÉS "Saunas castreñasenpoblados fortificados de Asturias y Galicia", en A. Coelho da Silva (coord.),Pedra formosa: arqueologia experimental, [Vila Nova de Famalicão], Câmara Municipal de Vila Nova de Famalicão; Museu Nacional de Arqueologia, 2007, págs. 66-92. Ángel VILLA VALDÉs, "Santuarios urbanos en la protohistoria cantábrica: Algunas consideraciones sobre el significado y la función de las saunas castrexas", Boletín del Real Instituto de Estudios Asturianos, 177 (2012), págs. 9-47

${ }^{53}$ Partiendo de Tim Ingold, "Materials against materiality", Archaeological Dialogues, 14-1 (2007), págs. 1-16.

${ }^{2} 4$ Ángel Villa Valdés y Luis Cabo PéRez, "Depósito funerario y recinto fortificado de la Edad del Bronce en el Castro del Chao de Sanmartín: argumentos para su datación", Trabajos de Prehistoria, 60-2 (2003), págs. 143-151.

${ }^{55}$ Xurxo Miguel Ayán Vila, Rafael María Rodríguez Martínez, Alfredo GonZález-Ruibal, Leonardo González Pérez, Álvaro Arizaga Castro y Manuel A. Franco Fernández, "Un espacio monumental de la $2^{\mathrm{a}}$ Edad del Hierro: el acceso SE al recinto superior de O Castro Grande de Neixón (Boiro, A Coruña)", en A. Fanjul Peraza (coord.), Estudios Varios de Arqueología Castreña, Teverga, Instituto de Estudios Prerromanos y de la Antigüedad, 2007, págs. 189-209.

${ }^{56}$ Patricia De Bernardo-Stempel y Marco V. García Quintela, "Población trilingüe y divinidades del castro de Lansbriga (NO de España)”, Madrider Mitteilungen, 49 (2008), págs. 254-290.
} 
Es relevante que en cierto número de casos señalados en esta tipología aparece epigrafía romana de carácter religioso. Así, en la zona de arte rupestre de la Edad del Hierro de Fentáns hay dos inscripciones rupestres. En Panoias y otras grandes rocas monumentalizadas esto es evidente. Pena Escrita es un ejemplo de roca con pilas. En la acrópolis del castro de San Cibrán también tiene una presencia notable. Estos ejemplos legitiman, también, que consideremos sus respectivos paralelos anepígrafos como variantes del modelo tal vez menos expuestas al influjo romano y de la escritura.

Esta tipología no es ni puede ser completa. Es precisa también una clasificación de las ubicaciones relativas de las estructuras enumeradas, porque es necesario constatar si se encuentran en el centro o en la periferia de los castros, si son estructuras extraurbanas o incluso de frontera, por ejemplo, y en el caso de las saunas si son subterráneas o no.

Además esta tipología basada en las formas de trabajar las rocas, tan útil como auxiliar para identificar los ítems a considerar, es equívoca porque en realidad los elementos diseccionados convergen en los mismos lugares pudiendo llegar a conformar entidades arqueológicas complejas que con frecuencia incluyen varios de ellos. Así la arquitectura ambigua aparece en las acrópolis de los castros (Castro Grande de Neixón en Boiro, Castro de Armea en Allariz, San Vicenzo en Avión), en áreas de arte rupestre (O Raposo en A Ferradura) o como forma de trabajar una gran roca monumentalizada (Pedra Furada en Coirós). Las pilas, a su vez, aparecen como un elemento integrado en cualquiera de los tipos identificados. Esta convergencia de elementos en los mismos lugares es el fundamento para distinguir y clasificar los diversos tipos al tiempo que apoya su interpretación ritual como probable, aunque desconozcamos los detalles de las prácticas.

En este artículo nos ocuparemos de las pilas en el contexto de la problemática general que acabamos de presentar. En concreto en las pilas del castro de Santa Mariña en Maside (Ourense) (Fig. 1), que relacionaremos con lugares similares. A través del análisis intentaremos tipificar el lugar en las tipologías definidas, incluyendo el paisaje arqueológico de la zona, y saber si efectivamente se puede inferir un significado cultual para este tipo de lugares. Sin embargo no pretendemos realizar un análisis a mayor escala que busque establecer un patrón de localización o una tipificación de estos lugares puesto que para ello deberíamos atender a la totalidad de sitios y a su distribución geográfica a gran escala, tarea que todavía es prematura.

Una cuestión añadida, matriz de la propuesta de A. Arizaga Castro y X. Ayán Vila $^{57}$ consiste en saber si estos sitios han tenido algún significado simbólico en

\footnotetext{
57 Álvaro Arizaga CaStro y Xurxo Miguel Ayán Vila, "Etnoarqueología del paisaje castreño...", págs. 473-479.
} 
las comunidades que las usaron, y si este se perpetuó y se reinterpretó en el tiempo, como parece haber ocurrido en Santa Mariña de Maside. Estas observaciones implican el reconocimiento de una temporalidad para estos elementos en la que es tan interesante su fecha de ejecución como cualquier otro momento en el que se transformaron y/o adquirieron un nuevo sentido.
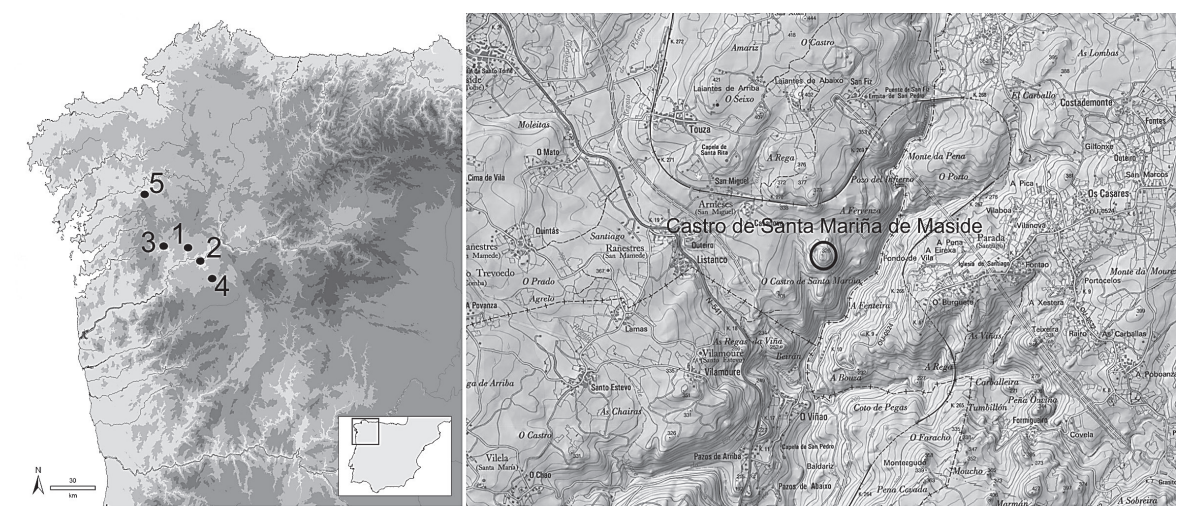

Fig. 1

Ubicación de los principales lugares citados en el texto: 1) Santa Mariña de Maside (Maside), 2) Castro de Santomé (Ourense), 3) Castro de San Vicenzo (Avión), 4) Santa Mariña de Augasantas (Allariz), 5) Castrovite (Silleda).

\section{Las Pilas de Santa Mariña de Maside}

El castro de Santa Marina se ubica en las llanuras norocciedentales de la provincia de Ourense conocida como Chaos de Amoeiro. Denominación del espacio situado en la cuenca media del Río Miño (desde Ourense ciudad) en forma de dos penillanuras localizadas la ambas orillas del río Barbantiño poco antes de desembocar en el Miño. El castro de Santa Mariña, con 326 m.s.n.m. en su cima, se encuentra delimitado en su lado E por el encajonado curso del río Barbantiño que funciona como una frontera natural, y por el O por el arroyo Listanco, ambos ríos se unen a los pies de la ladera $\mathrm{S}$ del monte para formar el valle que se extiende hasta la confluencia del Barbantiño con el Miño.

La parte más alta (croa en gallego) del castro de Santa Mariña es una superficie relativamente plana de aproximadamente media hectárea y muy bien acotada de forma natural. El acceso por la pista forestal procedente de Touza y San Miguel, se hace desde el $\mathrm{N}$ y a través del corte que se forma entre las dos cimas del monte. Algunas de las rocas que es preciso remontar subiendo hacia la cima occidental presentan huellas de actividad humana de difícil interpretación que 
pudieran corresponderse con restos de cantería (el granito del lugar es reputado en la zona por su calidad), y/o en algún caso quizás sirviesen para facilitar el acceso conformando una suerte de escalera muy rudimentaria. Las laderas meridional y oriental son muy abruptas y prácticamente intransitables, delimitando de forma natural la cumbre. Las hemos prospectado y sólo la meridional presenta una serie de rocas con grabados en forma de pequeñas cazoletas.

A lo largo de estas páginas mantenemos la toponimia oficial: "castro" de Santa Mariña, aunque la exploración efectuada hace que tengamos nuestras reservas sobre la posibilidad de que sea un hábitat. No hemos encontrado restos de estructuras habitacionales, ni restos de fortificación y los restos cerámicos son escasos. A partir de ahí podríamos pensar que no existía un hábitat, pero tal conclusión no es segura con los datos que manejamos actualmente.

En el año 2010 se llevó a cabo una prospección y documentación del sitio ante las referencias que apuntaban la presencia de grabados que podrían estar formando parte de un santuario rupestre de la prehistoria reciente ${ }^{58}$. Hemos reconocido una treintena de rocas con grabados rupestres y/o rebajes: pilas rectangulares, circulares, rebajes de gran profundidad, canales, posibles escaleras, cazoletas etc... También hemos encontrado una tumba y un sepulcro antropomorfos, que según la tradición popular se correspondería con el de Santa Mariña, y cuatro conjuntos de material cerámico. A continuación describimos las rocas más interesantes y complejas. Distinguimos dos grupos, uno situado en la cima, formado por las Rocas 1 a 3, y otro en un promontorio en la ladera SW, Roca 4:

\section{Roca 1}

Se sitúa en la parte NW de la croa, es una roca de forma irregular con tres caras, la E es plana y se encuentra a ras de suelo, en esta zona se encuentra grabada una pila casi cuadrangular de $50 \mathrm{~cm}$. por $55 \mathrm{~cm}$., con una profundidad que alcanza los $4 \mathrm{~cm}$. Las otras dos caras de la roca tienen una fuerte inclinación y presentan 10 rebajes de diversas formas y tamaños: uno ovalado de $12 \mathrm{~cm}$. por $15 \mathrm{~cm}$.; dos circulares de $9 \mathrm{~cm}$. y $11 \mathrm{~cm}$. de diámetro; cinco rectangulares, el mayor de 30 por $45 \mathrm{~cm}$; uno con forma arriñonada, esto es dos óvalos unidos por un surco ancho de $5 \mathrm{~cm}$. aproximadamente; y uno con forma irregular. La profundidad mayor de estos rebajes alcanza los $13 \mathrm{~cm}$. y la menor $6 \mathrm{~cm}$. Dada la inclinación de la roca se podrían interpretar estos rebajes como una especie de escalones para acceder a la pila que se sitúa en la parte superior (Fig. 2).

\footnotetext{
${ }^{58}$ Israel Barandela Rivero y José Manuel Lorenzo Rodríguez, Petroglifos de Ourense, Reflexións a un primeiro reconto... Israel Barandela Rivero, Ladislao Castro Pérez, José Manuel LOREnZo RodríGuez y Rafael OTERo, "Notas sobre los santuarios rupestres...”, págs. 47-68.
} 


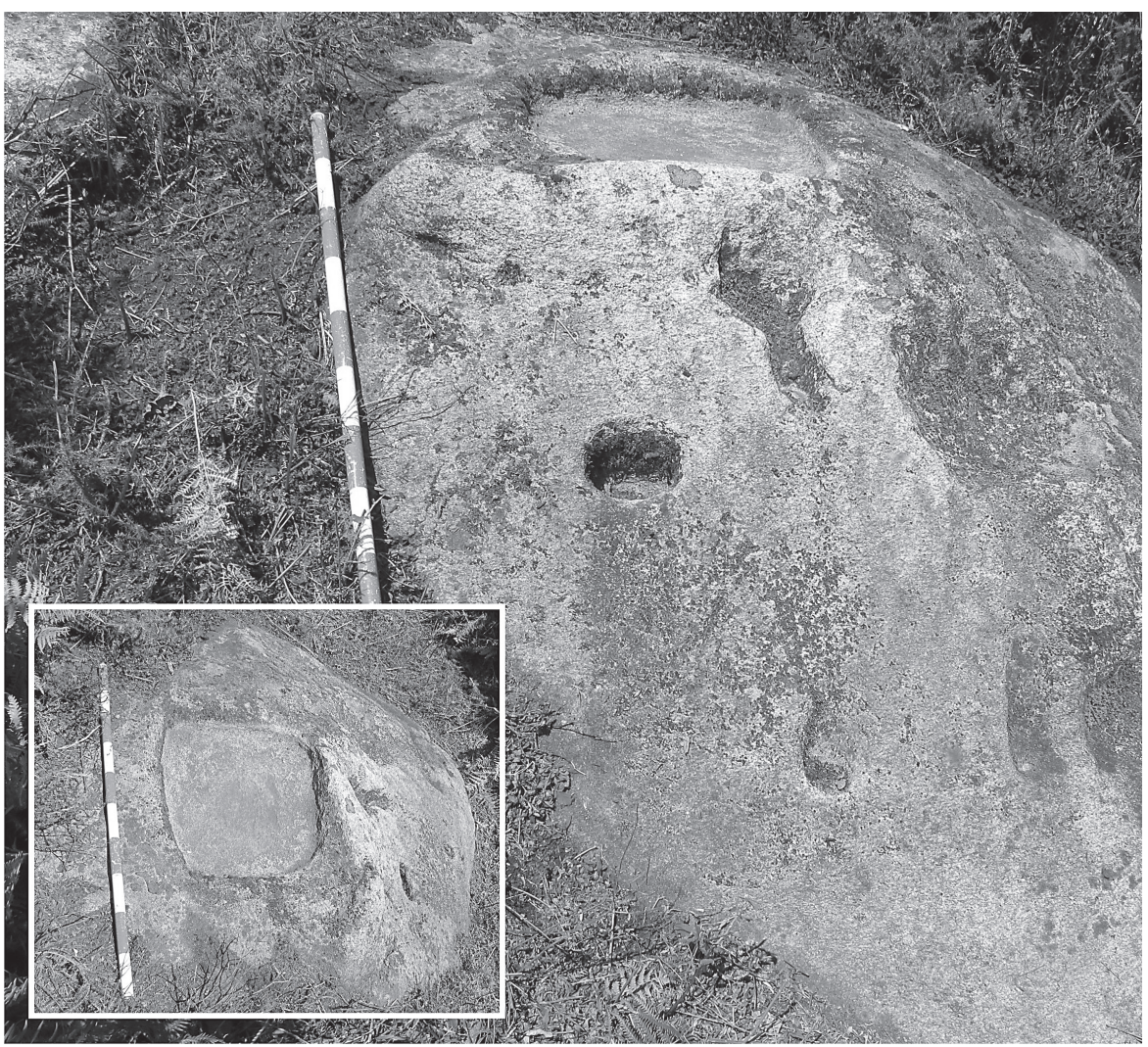

Fig. 2

Vista general de la roca $1 \mathrm{y}$ detalle de la pila.

\section{Roca 2}

Presenta la parte $\mathrm{W}$ ocupada por dos canales, uno que discurre en dirección NE-SW (de 0,7 m. de longitud) con una anchura máxima de $12 \mathrm{~cm}$. y mínima de $5 \mathrm{~cm}$., y otro en dirección E-W, de $0,9 \mathrm{~cm}$. de longitud y con una anchura que varía entre los $6 \mathrm{~cm}$. y los $11 \mathrm{~cm}$. Al lado de estos se encuentra una pila rectangular de $28 \mathrm{~cm}$. por $50 \mathrm{~cm}$., con una profundidad que llega a los $4 \mathrm{~cm}$. En la parte $S E$ además presenta un surco de $20 \mathrm{~cm}$. de longitud y una gran cazoleta, situada en la zona más extrema de la piedra aprovechando su forma triangular, de $27 \mathrm{~cm}$. de diámetro y $15 \mathrm{~cm}$. de profundidad (Fig. 3).

A un par de metros al $\mathrm{W}$ de esta roca aparece otra con una pila natural y unos canales partiendo de la misma, junto con varios rebajes y cazoletas. 


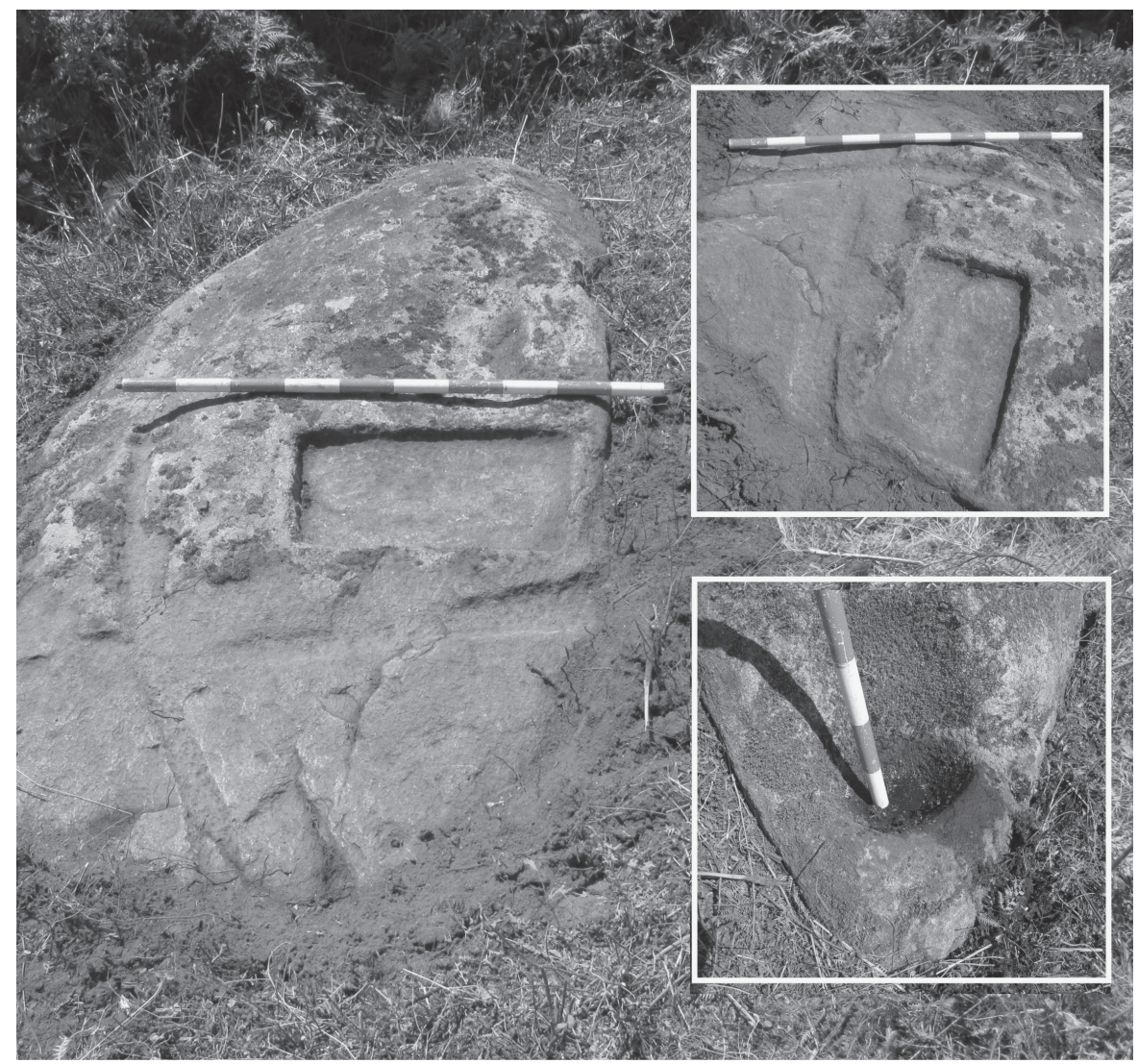

Fig. 3

Vistas generales de la roca 2 y detalles de la pila, canal y cazoleta.

\section{Roca 3}

Roca granítica a ras de suelo por la parte $\mathrm{W}$ y que levanta del terreno unos 70 $\mathrm{cm}$. por la parte E. Presenta un rebaje rectangular con bordes irregulares de $1 \mathrm{~m}$. por $0,80 \mathrm{~m}$. y de $15 \mathrm{~cm}$. en la parte más profunda. De este parten dos canales uno que va al $\mathrm{W}$ y que mide $40 \mathrm{~cm}$. y otro que mide $12 \mathrm{~cm}$. y que va al $\mathrm{E}$ terminando en un gran canal transversal situado en la parte oriental de la roca. Este canal mide unos $2 \mathrm{~m}$. de largo, su profundidad mayor es de $10 \mathrm{~cm}$. Su anchura varía entre los $18 \mathrm{~cm}$. y los $25 \mathrm{~cm}$. Esta pila, más irregular que las anteriores, parece haber tenido un origen natural y haberse modificado posteriormente de forma antrópica (Fig. 4). 


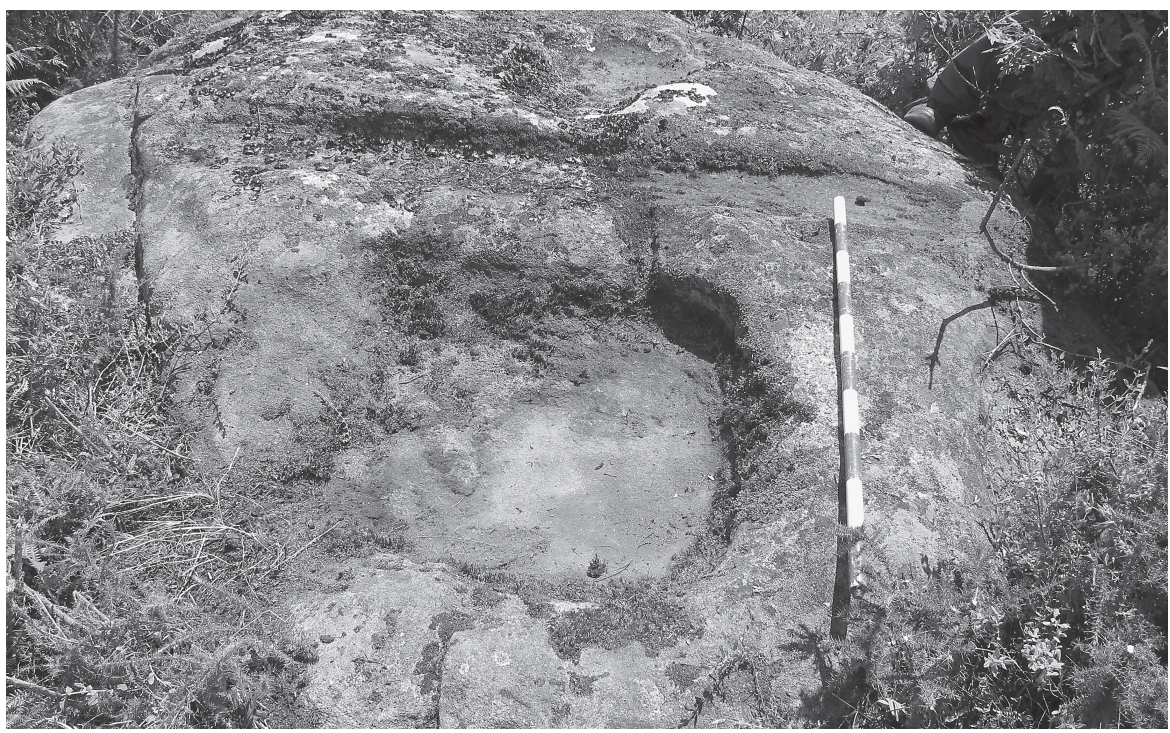

Fig. 4

Vista general de la pila de la roca 3.

\section{Roca 4}

Esta roca resalta especialmente tanto por sus dimensiones como por la cantidad y variedad de motivos. Está situada en un pequeño promontorio a los pies del ala SW del monte, en una zona denominada como "Porta da Santa", por donde pasa un antiguo camino real, antiguo ramal de la Vía de la Plata, según Barandela Rivero y Lorenzo Rodríguez ${ }^{59}$. Al lado de la piedra se sitúa un sarcófago y una tumba antropomorfa, considerados como el sitio donde está enterrada la santa. El afloramiento que se extiende por toda la cima del promontorio presenta numerosos rebajes por toda la superficie.

En la parte NE aparecen concentrados en una protuberancia de la roca veinticuatro rebajes circulares, ovalados y rectangulares, cuyo tamaño varía entre $45 \mathrm{~cm}$. por $8 \mathrm{~cm}$. y $40 \mathrm{~cm}$. por $4 \mathrm{~cm}$., y una profundidad entre $9 \mathrm{~cm}$. y $1 \mathrm{~cm}$. En esta zona además hay dos canales. En la parte central, aparecen seis rebajes de tamaños y formas variados, y un canal de grandes dimensiones que continúa por todo el afloramiento, mide $20 \mathrm{~cm}$. de ancho y tiene una profundidad media de 15 $\mathrm{cm}$. En la parte $\mathrm{N}$ hay un rebaje circular de $22 \mathrm{~cm}$. de diámetro y $10 \mathrm{~cm}$. de pro-

\footnotetext{
${ }^{59}$ Israel Barandela Rivero y José Manuel Lorenzo Rodríguez, "El culto a Santa Mariña...”, págs. 127.
} 
fundidad, tres rebajes circulares de menor tamaño dispuestos formando una línea y un canal. En la parte W aparecen dos rebajes circulares de $10 \mathrm{~cm}$. de diámetro y $8 \mathrm{~cm}$. de profundidad y $15 \mathrm{~cm}$. de diámetro y $16 \mathrm{~cm}$. de profundidad, y varios de menor tamaño y de forma ovalada. Cerca de estos y un poco más al S, aparece un rebaje rectangular de 45 por $20 \mathrm{~cm}$. por $4 \mathrm{~cm}$. de profundidad, otro de forma rectangular y alargada, dos circulares y otro en forma de "L" de $30 \mathrm{~cm}$. por 20 $\mathrm{cm}$. y $10 \mathrm{~cm}$. de profundidad que posiblemente continúe aunque actualmente está tapado por la vegetación. Hacia el $\mathrm{S}$ de este conjunto aparece una roca con dos pilas casi circulares que parecen haber tenido un origen natural pero haber sido modificadas de manera artificial posteriormente, la mayor mide $90 \mathrm{~cm}$. por $70 \mathrm{~cm}$. y $20 \mathrm{~cm}$. de profundidad. Al lado de ellas aparece un rebaje rectangular de $10 \mathrm{~cm}$. por $5 \mathrm{~cm}$. (Fig. 5).

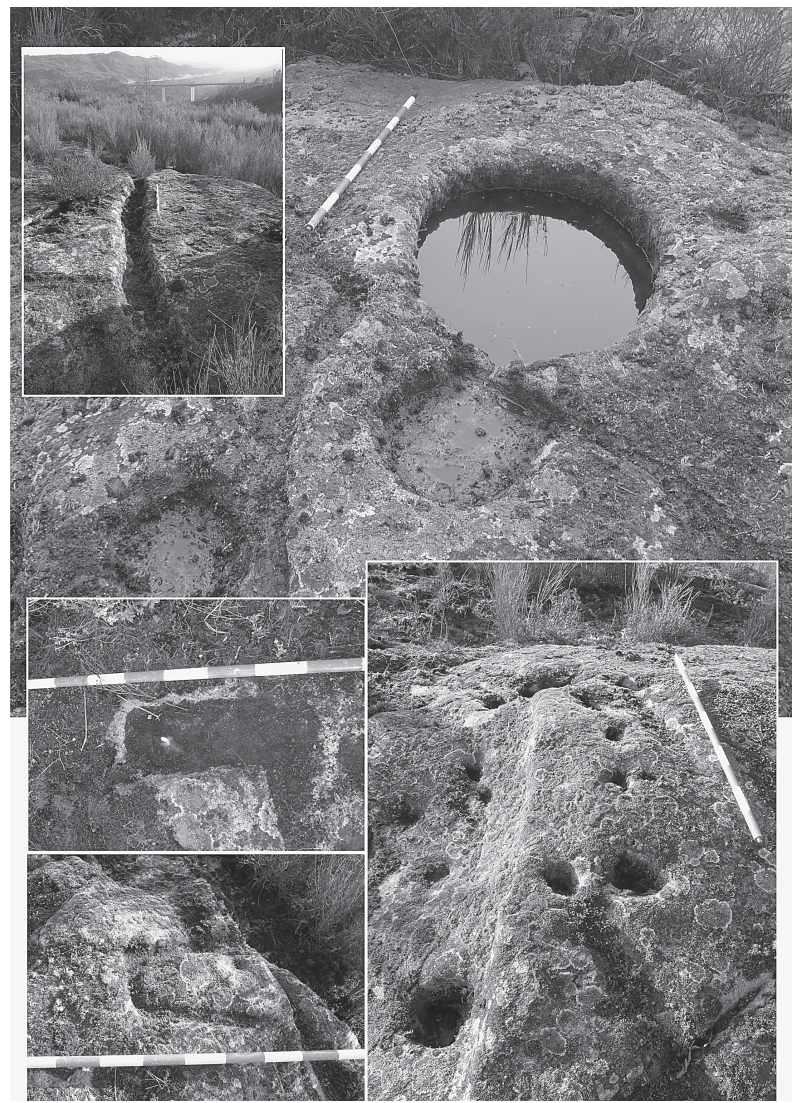

Fig. 5

Vista generales de los distintos rebajes de la roca 4. Las pilas de la foto se corresponden con las denominadas "pías da santa". 
Esta roca, según entrevista etnográfica, se corresponde con las “pilas de Santa Marina" siendo éstas el sitio donde se lavaba la santa. Efectivamente, tal y como describimos más arriba la piedra presenta unas pilas de gran tamaño de que se rodean de numerosos canales y rebajes artificiales. Justo del lado de estas pilas hay un rebaje artificial de menor tamaño que, según la historia oral facilitada por los vecinos, era donde depositaba Santa Mariña el jabón mientras se aseaba. No sólo estos rebajes están relacionados, según las tradiciones locales, con Santa Mariña sino que también en la croa varios receptáculos son reconocidos como las huellas del pie de la santa ${ }^{60}$.

Es interesante destacar que a escasos metros al E de la roca 4 y de la tumba antropomorfa aparece una gran concentración de piedras cuyas características homogéneas indican que se trata del derrumbe de una estructura arquitectónica. La vegetación tupida impide apreciar su extensión, por lo que nos es totalmente imposible aventurar a qué tipo de estructuras podrían pertenecer, ni saber si serían coetáneas de los rebajes o por el contrario podrían ser restos más recientes. En este sentido es destacable que Estévez $\mathrm{Puga}^{61}$ alude a una larga tradición local según la cual allí estuvo la capilla de Santa Mariña, más tarde trasladada al lugar de Outeiro, indicando que estos restos corresponderían a un eremitorio. Esto sería coherente con una historia recogida entre los vecinos durante los trabajos de prospección ${ }^{62}$ que señala que "antiguamente" la imagen de Santa Mariña se encontraba en el castro y que un habitante de la zona se ofreció a la santa, afirmando que si lo curaba subiría su imagen a un carro de bueyes y donde éstos pararan construiría una capilla dedicada a la santa. Esta historia da cuenta de la creación de una pequeña capilla de advocación a Santa Mariña situada en el lugar de Outeiro, a 1 km escaso en línea recta del monte de Santa Mariña y cuya puerta orientada SE mira directamente al castro.

Además de estas rocas descritas aparecen otras (en torno a veinticinco), sobre todo en la parte alta del monte, que presentan rebajes con diversas formas (rectangulares, ovalados, en forma de "L", arriñonados), canales y pilas. No vamos a describir cada una de ellas en este trabajo por una cuestión de espacio y porque ninguna presenta la cantidad, tamaño y variedad de rebajes que tenían las descritas más arriba. La única piedra que presenta un grabado que puede conformar una figura (aunque dudosa) está situada en el rellano a los pies del castro, en la parte SW, parece tener grabada una cruz en un cuadrado con varios apéndices y surcos anexos por la parte NW.

\footnotetext{
${ }^{60}$ Israel Barandela Rivero y José Manuel Lorenzo Rodríguez, “El culto a Santa Mariña...”, págs. 127.

${ }^{61}$ Xosé Estévez Puga et al., Maside e a súa antiga xurisdición, Ourense, Concello de Maside, 1994, pág. 149.

${ }^{62}$ Información facilitada por C.E., de 70 años, habitante del lugar de A Casanova (Maside).
} 
En cuanto a los materiales encontrados, son cuatro conjuntos con un total de 37 fragmentos cerámicos y 3 fragmentos de material constructivo. Dos conjuntos se localizaron se localizaron cerca de la Roca 4, provenientes de arrastres de tierra de zonas más altas quedando depositados encima de un afloramiento ubicado en una cota baja. Otro conjunto apareció en un abrigo rocoso natural en la parte NW del monte. El último conjunto es el resultado de la recuperación de material disperso por la croa del monte. La mayor parte de las piezas tienen adscripción en la Edad del Hierro, perteneciendo probablemente de su fase final o en torno al cambio de era, se trata de cerámica doméstica con abundantes restos de hollín en el exterior y alguno en el interior.

\section{Clasificando Santa Mariña de Maside}

Es posible contextualizar este conjunto arqueológico de dos formas complementarias, conforme enunciábamos en el apartado 2. Por una parte, usaremos la tipología que hemos definido, incluyendo los aspectos relevantes destacados por otros autores. Por otra parte, es importante la configuración arqueológica a mayor escala, pues el valle del Barbantiño presenta una singular variedad de espacios rituales que permite precisar los límites y convergencias entre los tipos identificados. Una vez establecido el contexto tipológico regional expondremos las observaciones que remiten a su cronología y a su interpretación como lugar destinado a la función ritual.

\subsection{Una cuestión de formas: identificando el tipo}

El conjunto examinado, por su apariencia, entra de lleno en las categorías presentadas en el apartado 2, pero también presenta rasgos específicos como ocurre, por lo demás, con cada caso examinado de forma monográfica. También conviene separar para este análisis el conjunto arqueológico de la cima y el conjunto de la ladera SW por sus evidentes diferencias, aunque posiblemente el segundo sea resultado de una derivación o continuidad del primero (ver más abajo). Las rocas trabajadas de la croa se clasifican en la categoría de rocas con pilas. Veamos otros ejemplos.

El primero es el Altar da Pena Escrita (Vilar de Perdizes, Montealegre). Se trata de una roca monumentalizada donde destaca una pila cuadrangular central y la asociación con motivos grabados típicos del Estilo Esquemático Atlántico ${ }^{63}$ como son las herraduras. Es una estructura esculpida en un afloramiento granítico a ras de suelo de modo que no destaca en el paisaje, está formada por tres estrechos escalones rodeada por un triple marco, recordando morfológicamente

\footnotetext{
${ }^{63}$ Manuel Santos Estévez, Petroglifos y paisaje social... págs. 123-178.
} 
a un altar votivo con su foculus. Inmediatamente después del último escalón, hay dos rebajes cuadrangulares de idénticas dimensiones dispuestos en un eje simétrico respecto a la cavidad rectangular. Se han encontrado dos altares votivos en las cercanías cuyas dimensiones encajan perfectamente con las de las mencionadas cavidades ${ }^{64}$. Ahora bien, A Pena Escrita presenta un predominio de formas cuadrangulares, ángulos y aristas que tal vez probablemente estuvieron muy bien marcadas inicialmente, mientras que en las rocas de Santa Mariña no hay ese predominio ortogonal.

Otro paralelo lo proporciona las llamadas "Pioucas da Santa" en Armea (Santa Mariña de Augas Santas, Allariz) (Fig. 6) situadas en la base de la ladera E del castro de Armea. Consiste en dos grandes pilas rectangulares con una semejanza destacable con Pías dos Mouros. El sitio se relaciona con un episodio del martirio de Santa Mariña con lo que constatamos en las dos Santas Mariñas que el folclore de esta santa se relaciona con las pilas.
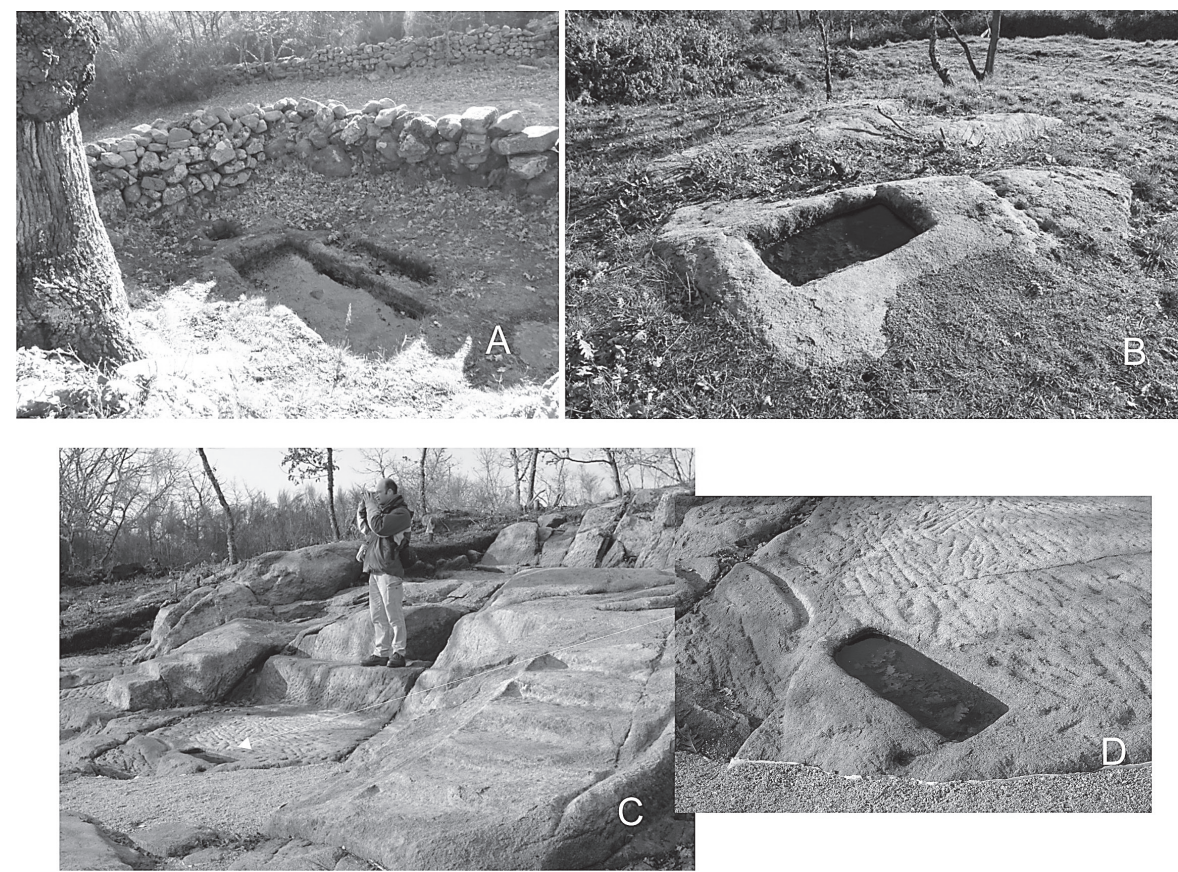

Fig. 6

A) "Pioucas da Santa" de Armea (Santa Mariña de Augasantas, Allariz).

B) y D) Pilas rectangulares situadas en el santuario Armea. C) Santuario de Armea.

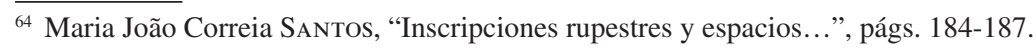


Estos dos ejemplos corresponden al tipo de rocas con pilas aisladas y ambos están en zonas llanas, directamente relacionadas (Pioucas da Santa) o no (Pena Escrita) con castros. Sin embargo las pilas de Santa Mariña de Maside conforman un conjunto que es necesario comprender como tal pues ocupan, monumentalizándolo, un lugar conspicuo del paisaje. En este sentido cabe plantear la duda sobre si un trabajo arqueológico más intensivo que el efectuado podría llevar a la identificación de una gran roca monumentalizada en el conjunto de la cima (como lo es, de manera específica, la roca 4 en la ladera SW). A expensas de ese eventual trabajo podemos señalar otros tres paralelos compuestos por series de pilas situadas en castros.

El primero se encuentra en el Castro de Santomé. Está situado a $3 \mathrm{~km}$ al E de la ciudad de Ourense en un pequeño promontorio junto al cañón que forma el río Loña. En él se han realizado excavaciones desde los años 80 que han sacado a la luz, además del castro, un asentamiento galaicorromano con una etapa altoimperial y otra bajoimperial, a la que pertenecen las estructuras visibles en la actualidad ${ }^{65}$.

El castro presenta una visibilidad amplia hacia el $\mathrm{W}$, hacia la zona del valle del Miño donde se asienta la ciudad de Ourense, pues N y S tienen cotas mucho más altas y sólo el cauce del Loña abre ligera y parcialmente la visibilidad hacia el naciente. En el castro aparecen cuatro conjuntos de pilas (Fig. 7) en la parte $\mathrm{S}$ del castro. El primer grupo se encuentra en la parte alta del yacimiento, cerca de la zona excavada. Se trata de pilas que se sitúan hacia el E en un afloramiento que cierra la visibilidad hacia el W. Son tres pilas rectangulares con rebajes adosados y otra circular por uno de sus lados y angulada por el otro, en forma de cuarto de círculo. Otro conjunto aparece al SE, ladera abajo, mirando al cañón del Loña. Allí destaca una pila rectangular de gran profundidad con canal, diversos rebajes rodeándola y restos de diversidad de trabajos en la roca que dificultan la lectura del conjunto. Al W de este conjunto a una cota similar, aparece otra pila rectangular con varios rebajes circulares a escasos centímetros, y una visibilidad amplia hacia el W. Es discutible la función del conjunto de pilas situado en la parte del castro destinada a habitación. Sin embargo, el conjunto situado sobre el río Loña, por su disposición, parece carecer de cualquier clase de función utilitaria: una de las rocas con pilas presenta una escalera que lleva... al precipicio. Podemos señalar además que justo por encima del castro de Santomé el embalse de Castadón controla el curso del Loña. Sin esta obra, el río conformaría un ruidoso rápido que formaba parte singular del paisaje local del castro.

\footnotetext{
${ }^{65}$ Isabel Peralta Bejareno, Xulio Rodríguez González y Manuel Xusto Rodríguez, Conjunto arqueológico-natural de Santomé: excavación, consolidación y musealización de un sector del Castro, A Coruña, Fundación Pedro Barrié de la Maza, 2004.
} 


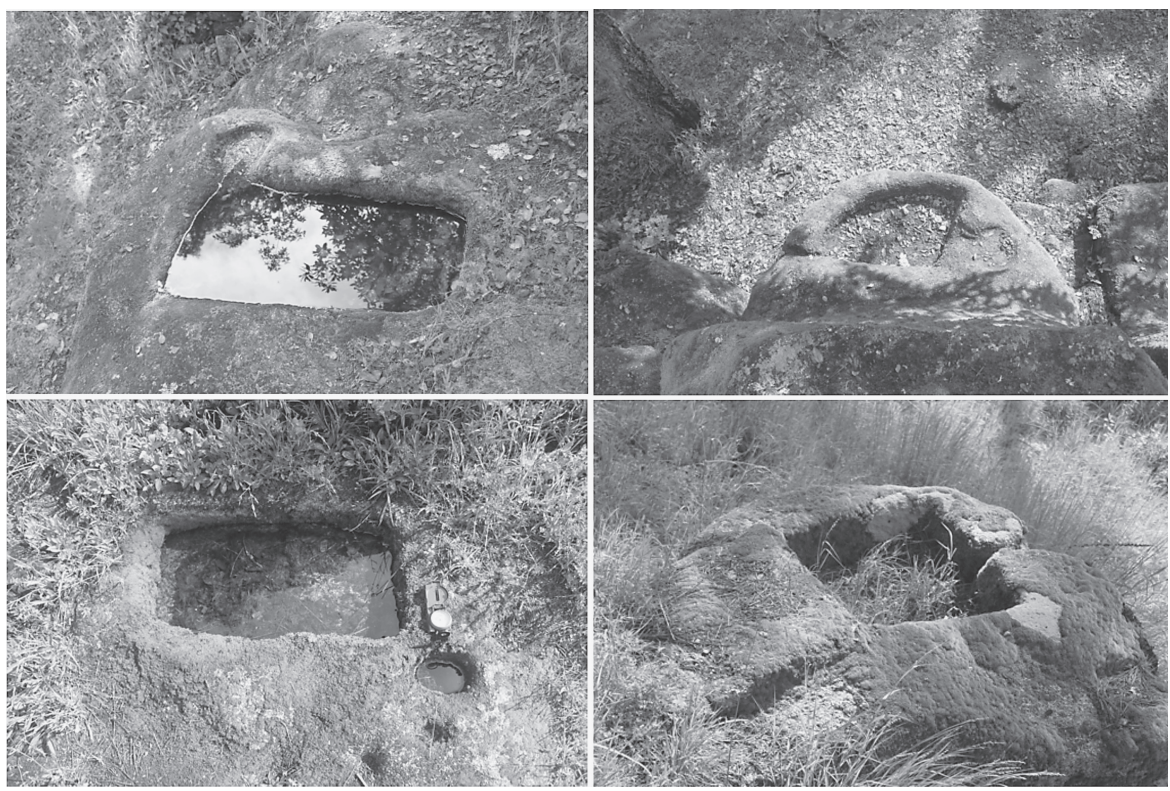

Fig. 7

Pilas del castro de Santomé, las superiores se sitúan en la parte más alta del castro, y las inferiores se en una cota más baja cerca del río Loña.

Nuestro segundo ejemplo está en el castro de San Vicenzo (Avión). Las pilas aparecen en dos localizaciones diferenciadas.

Una está en la parte más elevada de la croa formada por un afloramiento rocoso de grandes dimensiones $(7 \mathrm{~m}$. por $13 \mathrm{~m}$.) sobre cuya superficie se distinguen dos zonas (Fig. 8): una hacia el S con pilas, algunas posiblemente trabajadas a partir de elementos naturales, y otra rectangular claramente artificial con unas dimensiones de $30 \mathrm{~cm}$. en el eje NE-SW por $52 \mathrm{~cm}$. en el eje NW-SE, y una profundidad de $10 \mathrm{~cm}$. Inmediatamente al $\mathrm{E}$ de esta roca hay un rebaje rectangular de $10 \mathrm{~cm}$. por $14 \mathrm{~cm}$. con una profundidad de $10 \mathrm{~cm}$. Esta roca también presenta cinco rebajes dispuestos formando una línea y situados en la parte con más pendiente que podrían servir de peldaños de acceso. El mayor presenta unas medidas de $20 \mathrm{~cm}$. por $17 \mathrm{~cm}$. y el menor de $13 \mathrm{~cm}$. por $10 \mathrm{~cm}$. A la derecha de esta línea de rebajes aparece otro con unas dimensiones de $14 \mathrm{~cm}$. por $10 \mathrm{~cm}$. La zona $\mathrm{N}$ presenta indicios de una fragmentación del granito provocada en parte por fuegos intencionales encendidos sobre roca de forma continuada y/o intensa, aunque es imposible fijar a qué época pertenecerían. Éste es un ejemplo claro del tipo "gran roca monumentalizada" que hemos definido. 
En la ladera E del castro, a unos $100 \mathrm{~m}$. de esta roca y a una cota 10 ó 12 metros por debajo, aparecen dos pilas que podemos comparar con las que hemos visto en Santa Mariña de Maside y el castro de Santomé. Tienen una forma ovalada de origen tal vez natural, pero parece evidente que se han trabajado, también dominan un paisaje espectacular cuyo punto más conspicuo es Pena Corneira hacia el E (Fig. 8).

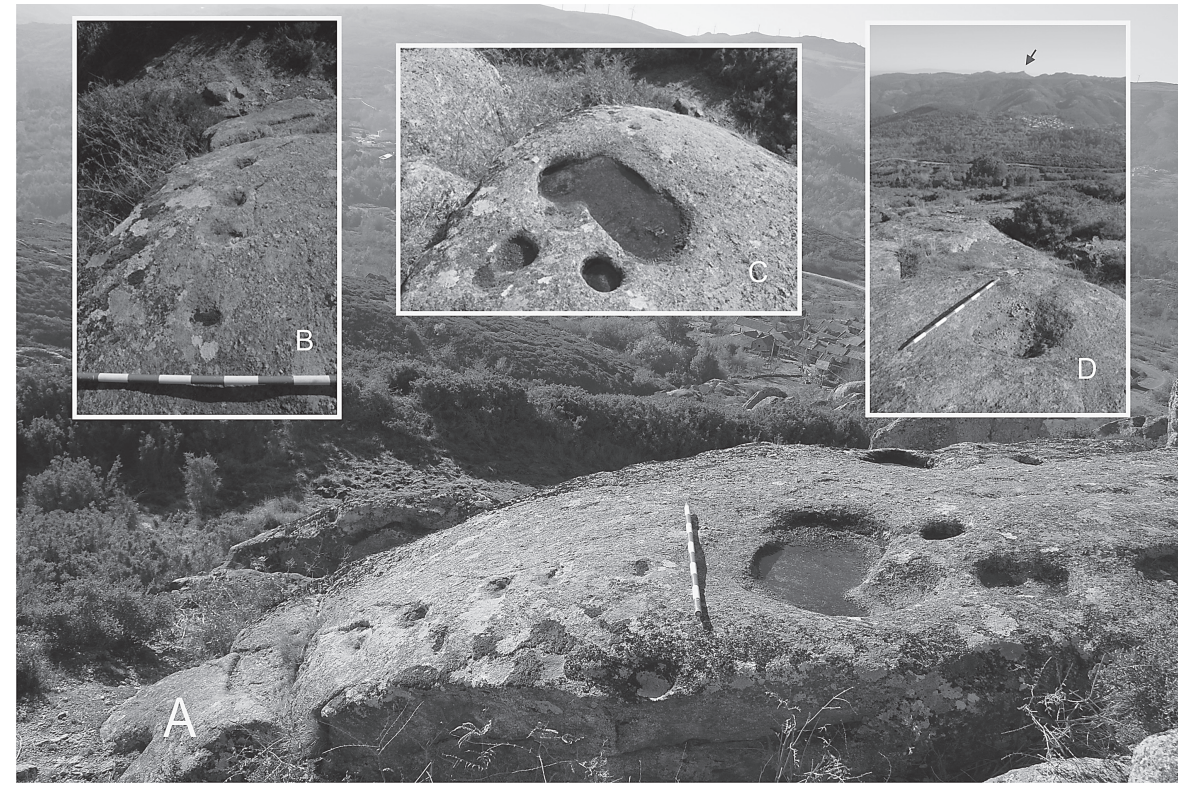

Fig. 8

Castro de San Vicenzo: A) Gran roca situada en la parte más alta de la croa del castro con rebajes a modo de escalera y piletas, B) y C) Detalles de la anterior, D) Pileta situada en la ladera SE del castro. Obsérvese al fondo, marcado por una flecha, el gran afloramiento de Penacorneira.

El tercer ejemplo que podemos mencionar es el de Castrovite (Silleda) con una capilla en su cima con advocación a Santa Mariña. Este castro, muy alterado en la actualidad, presenta en la parte más alta una roca granítica de aproximadamente $5 \mathrm{~m}$. por $5 \mathrm{~m}$. con cinco pilas, dos de las cuales son muy regulares y profundas (desde $11 \mathrm{~cm}$. a $14 \mathrm{~cm}$. de profundidad) y parecen tener un origen artificial (Fig. 9). No encontramos indicios de más rocas con pilas en este castro pero el sitio puede ser un buen ejemplo de cómo la advocación a Santa Mariña se asocia con frecuencia con pilas.

A la vista de estos paralelos se aprecia que las pilas no aparecen al azar sobre la extensión del castro, sino en determinados puntos con amplia visibilidad y es- 
pecialmente relevantes, además en algunos casos mirando a un río cercano. Esto también ocurre en los castro de Montealegre y Troña, o en el Pico Sacro, las únicas pilas que existen ocupan lugares destacados, justo en el borde más abrupto del yacimiento o, en el caso de Troña, frente al petroglifo serpentiforme ${ }^{66}$.

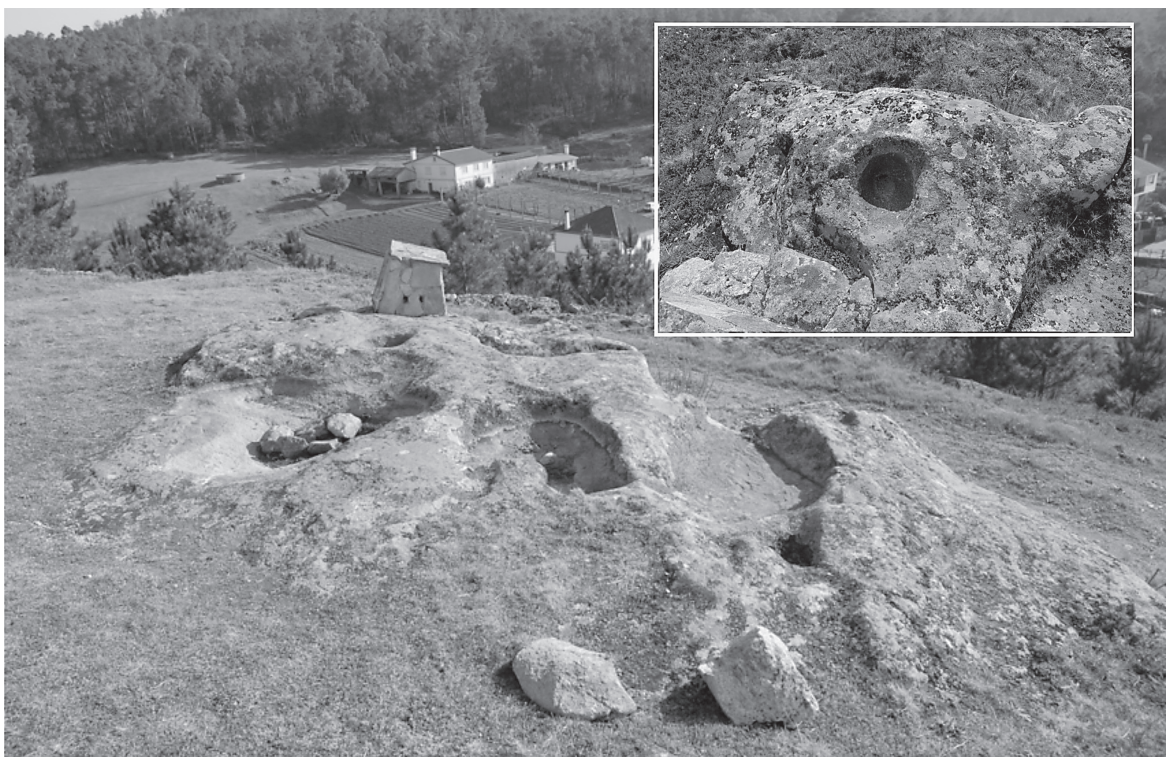

Fig. 9

Vista general y de detalle de las piletas de Castrovite.

\subsection{Una cuestión de relaciones: el paisaje sagrado del Barbantiño}

El paisaje arqueológico en torno al Barbantiño dominado por el monte de San Trocado, donde hay un castro de la primera Edad del Hierro, está en proceso de estudio desde hace más de 12 años. Aunque el castro de San Cibrán de Las, el yacimiento más significativo de la zona, se estudia de forma discontinua desde los años 20 del siglo pasado. También se ha intervenido arqueológicamente en A Ferradura y nuevas prospecciones sugieren que el tema no está agotado a poco que se amplíe la intensidad o la extensión del área de estudio. Valga como muestra el presente trabajo sobre Santa Mariña de Maside. La razón de esta riqueza arqueológica se debe a dos factores contrapuestos. Por un lado el valle del Barbantiño es el paso natural entre el valle del Miño y el N de Galicia, por lo que

\footnotetext{
${ }_{66}$ Álvaro Arizaga Castro y Xurxo Miguel Ayán Vila, "Etnoarqueología del paisaje castreño...", págs. $477-478$
} 
acumula toda clase de infraestructuras de comunicación (carreteras, autopistas, autovías, tren, AVE). Por otro lado, es una zona sometida a una importante caída de población que ha facilitado la conservación del paisaje agrario tradicional y de los restos arqueológicos que llevaba asociado, esto también ha hecho posible que la técnica de la prospección haya sido particularmente fructífera.

Sobre las alturas que limitan el valle se habían identificado dos santuarios correspondientes a sendos tipos de los indicados en el apartado 2. Por una parte el área de arte rupestre de A Ferradura presenta indicios de un uso muy prolongado a lo largo del tiempo, incluyendo de forma inequívoca la Edad del Hierro ${ }^{67}$. Por otra parte la croa del castro de San Cibrán de Las destaca por su elenco de inscripciones que nos da a conocer el panteón de los habitantes del castro ${ }^{68}$. Ambos lugares están sobre las márgenes izquierda y derecha del río Barbantiño, respectivamente, y se miran como en espejo, pues A Ferradura tiene toda su visibilidad orientada hacia el W mientras que la visibilidad de la croa de San Cibrán de Las se orienta exclusivamente hacia el E. Además entre ambos lugares existe una compleja red de relaciones arqueoastronómicas que inciden en la necesidad de considerar ambos lugares de forma sistémica. A partir de aquí nos preguntamos cómo se integra Santa Mariña en este paisaje.

Podemos comenzar a responder subrayando que esta última se ubica en una pequeña colina situada sobre la confluencia de ríos Barbantiño y Listanco. También A Ferradura, aunque de una forma menos directa, en una altura que domina la confluencia del Barbantiño y el Miño. Este rasgo topográfico recuerda la topografía de Betanzos identificada como nemitus en la toponimia medieval con la palabra derivada del celta nemeton. Con esto no pretendemos afirmar que debamos definir estos lugares con esa palabra, pero la analogía topográfica es evidente.

Por otra parte, el castro de Santa Mariña completa, por así decirlo, el conjunto formado por A Ferradura y la croa de Las. En efecto, estas estructuras están al E y el O del valle, mientras que Santa Mariña cierra el vértice N del valle. Señalemos que hay otros montes cercanos, algunos más altos y todos con abundantes afloramientos rocosos, pero sólo Santa Mariña es el primer monte que domina por completo el valle en esa posición. Además desde la cima y la ladera meridional hay una visibilidad directa con A Ferradura, a 3,5 km, y con San Cibrán de Las y San Trocado, a unos 5,5 km y 6,5 km respectivamente (Fig.10).

Tipológicamente distinguimos la gran roca de la ladera meridional del conjunto arqueológico de la cima en el que nos detendremos. Si consideramos la

\footnotetext{
${ }^{67}$ Marco Virgilio García Quintela y Manuel Santos Estévez, Santuarios de la Galicia... Yolanda Seoane Veiga, María Pilar Prieto Martínez y Cecilia Dalzovo, "Bell beaker findings...". ${ }^{68}$ Patricia De Bernardo-Stempel y Marco V. García Quintela, "Población trilingüe y divinidades...", págs. 254-290.
} 
forma de trabajar las rocas estamos ante un caso de rocas con pilas con la particularidad de que constituyen una serie, como en los castros de Santomé y San Vicenzo. Pero si consideramos la topografía del lugar estamos ante un espacio perfectamente acotado de forma natural por las pendientes del monte en tres de sus lados, N, E y S, y hacia el W por una cresta rocosa de escasa altura relativa con respecto al suelo de la cima (1,5-2 m.) que tiene como efecto cerrar por completo la visibilidad en esa dirección. Es en ese espacio acotado donde están las rocas que estudiamos. Esta disposición es en todo conforme a lo observado en A Ferradura a una escala menor. A Ferradura también es un área muy bien delimitada de forma natural, con visibilidad cerrada hacia el E y con una gran serie de rocas con grabados. Cambia entre Santa Mariña y A Ferradura la naturaleza del trabajo sobre las rocas: pilas o grabados rupestres.

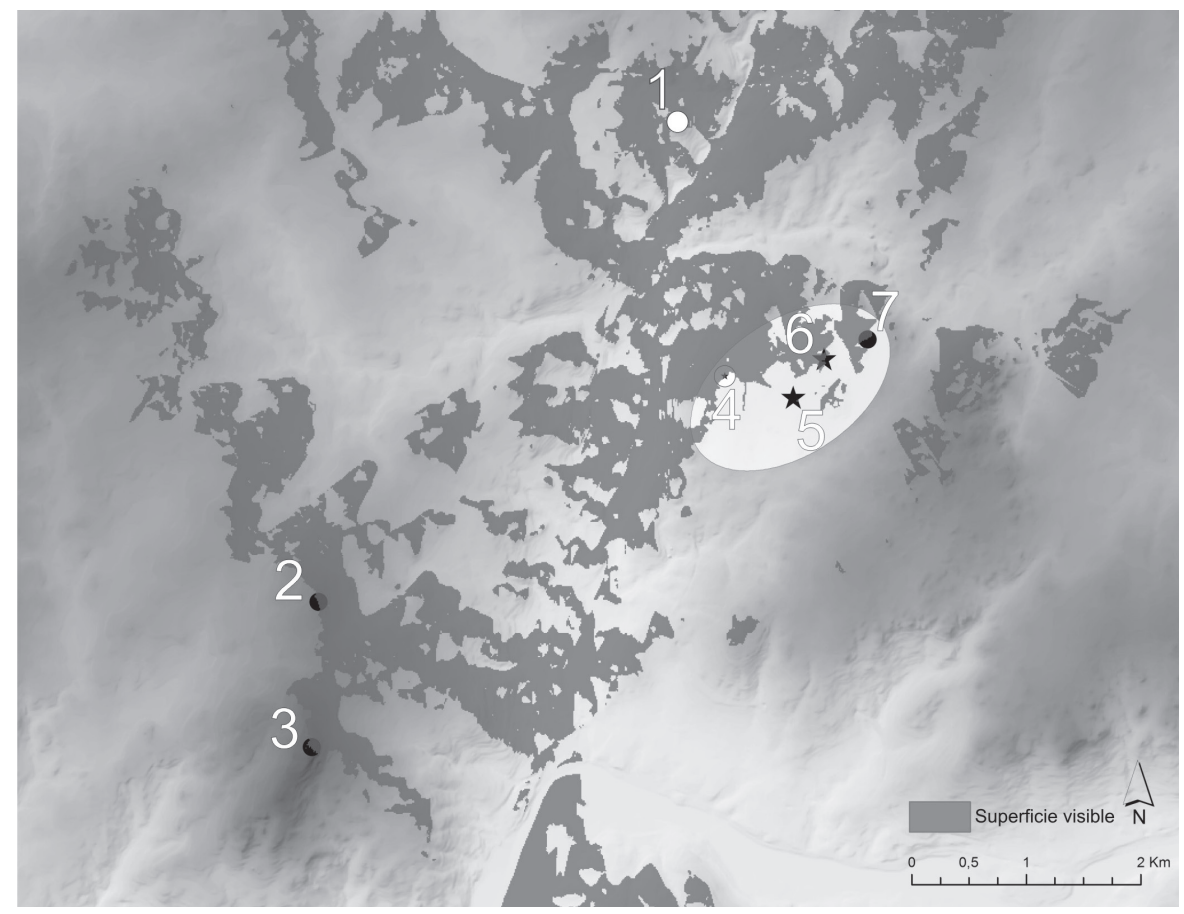

Fig.10

Mapa de visibilidades desde el castro de Santa Mariña: 1) Santa Mariña de Maside, 2) San Cibrán de Lás, 3) Castro de San Trocado, 4) Castro de A Zarra, 5) Petroglifo de O Raposo, 6) Pedra das Ferraduras, 7) Coto do Castro (estos 4 últimos se sitúan en la estación conocida como A Ferradura). El cálculo de visibilidad se ha realizado sobre un modelo digital de elevaciones creado a partir de la cartografía oficial 1:5000 de la zona. 
Ahora bien, si tenemos en cuenta la magnitud del espacio considerado y su orientación, la cima de Santa Mariña parece un calco de la disposición de la croa del castro de San Cibrán de Las. La diferencia sustancial es la forma de acotar el espacio, artificial en Las y natural en Santa Mariña. El lienzo W del muro de la croa de Las limita por completo la visibilidad en esa dirección, función que cumple en Santa Mariña el afloramiento rocoso indicado. No hay inscripciones en Santa Mariña, pero es pertinente indicar que las inscripciones encontradas en el año 2003 en San Cibrán de Las con menciones a divinidades indígenas aparecieron en el interior de la croa sobre un gran afloramiento rocoso situado junto a su muro occidental ${ }^{69}$. Por ello consideramos posible interpretar la disposición topográfica de Santa Mariña con sus rocas trabajadas con pilas como una suerte de "croa salvaje". La orientación al naciente de ambos espacios responde a los usos habituales de la actividad ritual según la tradición indo-europea ${ }^{70}$. Señalemos por último, aunque tal vez sea irrelevante, que la parte del recinto de Las visible desde Santa Mariña se limita a la croa y a la mitad E del castro. Sugerimos, por lo tanto, que se trata de un mismo modelo de implantación en el espacio de alguna clase de actividad ritual cuyos pormenores desconocemos con variantes marcadas por el predominio relativo de la monumentalidad natural (Santa Mariña) o artificial (San Cibrán de Las).

\subsection{Una cuestión de tiempo: de la estratigrafía arqueológica a la interpretatio cristiana}

En el estudio de A Ferradura se han detectado dos grandes momentos de acción humana que vienen dados por la presencia en la roca de A Ferradura de motivos propios del Estilo Atlántico de Arte Rupestre y motivos propios del Estilo Esquemático Atlántico fechados en la segunda Edad del Hierro. Las dataciones de San Cibrán ${ }^{71}$ nos remiten a unas fechas entre el II a. C. y el I-II d. C. En la segunda Edad del Hierro es cuando aparecen formas de organización social más compleja, con un nuevo modelo de ocupación del territorio en el S de Galicia y $\mathrm{N}$ de Portugal basado en grandes castros como el de San Cibrán. Es significativo que uno de los teónimos de San Cibrán, SADV VLADV, hace referencia a la

\footnotetext{
${ }^{69}$ Yolanda Álvarez González, Luis López GonzÁlez, Miguel Ángel López y Pedro López BARJA, "Dos inscripciones inéditas del castro de San Cibrán de Las (San Amaro-Punxín, Ourense)", Paleohispánica, 4 (2004), págs. 235-244.

${ }^{70}$ Marco Virgilio García Quintela y Manuel Santos Estévez, Santuarios de la Galicia...

${ }^{71}$ Yolanda Álvarez GonzÁlez, Luis López GonzÁlez, y Miguel Ángel López, "La ocupación del espacio común y privado en la citania de San Cibrán de Lás", Revista Aquae Flaviae, 41 (2009), págs. 195-209 (Actas del congreso transfonteiriço de Arqueología, 3-5 Octubre 2008-Montealegre).
} 
soberanía (análisis lingüístico de P. De Bernardo-Stempel ${ }^{72}$ ). Esta organización social compleja se expresa, en el plano religioso, a través de fiestas y asambleas presididas por diferentes autoridades, por distintos motivos y en diferentes lugares del territorio gobernado por esa autoridad, según un modelo conocido en la Edad del Hierro en toda Europa.

En el caso de Santa Mariña pudo existir una larga pervivencia del sitio como lugar de culto. La cerámica encontrada remite a la etapa final de la Edad del Hierro o del cambio de era y la estructura del posible eremitorio nos lleva a épocas históricas. La inclusión en la historia de la santa de los elementos arqueológicos ("As pías de Santa Mariña" y los rebajes en forma de "pie" de la croa) pueden indicar que la zona tenía un sentido simbólico o ritual para los habitantes de la zona que fue necesario cambiar con la llegada del cristianismo, utilizándose la narrativa de Santa Mariña, siguiendo un modelo cuyos perfiles reconocemos poco a poco ${ }^{73}$. De confirmarse, este hecho nos indicaría una continuidad del sitio como espacio ritual (no sabemos si con interrupciones) desde la protohistoria hasta la Edad Media e incluso hasta tiempos recientes, como lo atestigua la relación viva entre el castro, el santuario y la aldea: en una entrevista realizada por Barandela Rivero y Lorenzo Rodríguez ${ }^{74}$ se recoge la información de que "hubo un tiempo" en el que se iba en peregrinación hasta el castro, donde se hacía una homilía y una rogativa destinada a recoger buenas cosechas. El 18 de Julio (día de Santa Mariña) era obligada la visita al castro, en este momento el agua de las pilas se consideraba sanadora.

Por otro lado, M. Almagro ha publicado un ensayo sobre la hagiografía de Santa Mariña de Augas Santas donde intenta identificar las huellas de los tipos de sacrificio atestiguados en el mundo celta antiguo ${ }^{75}$ y con otros argumentos se ha tratado la particular relación que se establece en esa misma hagiografía y lugar entre la leyenda santa, el paisaje local y otras tradiciones sobre personajes femeninos creadores del paisaje ${ }^{76}$. Con independencia del valor de estas aproxi-

\footnotetext{
72 Patricia De Bernardo-Stempel y Marco V. García Quintela, "Población trilingüe y divinidades...”, págs. 244-246

${ }^{73}$ Marco Virgilio García Quintela y Manuel Santos Estévez, Santuarios de la Galicia... Marco Virgilio García Quintela y Yolanda Seonne-Veiga, "La larga vida de...”, págs. 243-266.

${ }^{74}$ Israel Barandela Rivero y José Manuel Lorenzo Rodríguez, "El culto a Santa Mariña...", págs. 127.

${ }^{75}$ Martín Almagro Gorbea, "La triple muerte en el Libro del Buen Amor y la leyenda de Santa Mariña de Aguas Santas", en Martín Almagro Gorbea, Literatura hispana prerromana. Creaciones literarias fenicias, tartesias, iberas, celtas y vascas, Madrid, Real Academia de la Historia, (2013), págs. 376-413.

${ }^{76}$ Marco Virgilio García Quintela, "Mariña concubina, Mariña virgen, Boand adúltera: fecundidad extramarital y genealogía de los paisajes" en $\mathrm{M}^{\mathrm{a}}$ Tausiet, H. Tropé (eds.), Folclore y leyendas en la península ibérica. En torno a la obra de François Delpech, [en prensa].
} 
maciones para la comprensión de nuestro objeto de estudio concreto parece clara la opción seguida en poblaciones rurales de escoger a Santa Mariña como patrona cristiana de lugares de culto preexistentes en algún momento indeterminado de la Antigüedad Tardía.

Si bien la continuidad religiosa parece clara no es fácil saber si hubo distintas fases en las rocas grabadas de Santa Mariña. Si atendemos a la hipótesis tipológica de M.J.C. Santos expuesta en el apartado 2, podríamos reconocer un primer momento marcado por las pilas más simples de forma circular y con canales. $\mathrm{Si}$ esta fase fue pertinente tal vez no fue muy intensa, puesto que este tipo de pilas no son abundantes. Un segundo momento podría corresponder a las pilas rectangulares y los rebajes más complejos, dotando al área de mayor entidad formal, "monumentalizando" el lugar para conformar la "croa salvaje". Esta segunda fase podría corresponderse con la segunda Edad de Hierro cuando la creciente complejidad social parece correr en paralelo con la conformación de nuevas y/o más conspicuas materializaciones de la religiosidad.

Incluso podemos sugerir un paso más trayendo a colación el ejemplo de Castrovite, donde se ha documentado una larga secuencia de ocupación que comienza a inicios del S. VIII a.C y que perdura hasta el S. I a.C ${ }^{77}$. De este modo considerando la forma de las pilas y otros elementos arqueológicos asociados se puede sugerir una diacronía en la tipología de las pilas. Las más antiguas serían las más informes o aquellas naturales o con ligeras modificaciones antrópicas ( $1^{\mathrm{a}}$ Edad del Hierro, Castrovite). En la $2^{\mathrm{a}}$ Edad del Hierro se ubicarían las que presentan formas cuadrangulares mejor trabajadas y a veces integradas en rocas estructuradas más complejas (castro de Santa Mariña, castro y santuario de Armea, Pedra Furada, fase antigua de Panoias). Finalmente, quedarían para la época romana las que incluyen formas ortogonales más marcadas y, en algunas ocasiones, inscripciones. Esta clasificación coincide grosso modo con la propuesta por M.J.C. Santos ${ }^{78}$ descrita al principio de este artículo. Ahora bien, nuestra propuesta es una mera aproximación provisional, puesto que cuando las secuencias de ocupación de los castros son largas es muy difícil vincular las pilas a un momento concreto de las mismas, y el hecho de atribuirlas como en el caso de Castrovite a la $1^{\circ}$ Edad del Hierro, se debe a que las únicas pilas conocidas en el yacimiento son del tipo más informe y están ubicadas en la terraza superior de un yacimiento en el que se ha documentado una fase de ocupación correspondiente a la primera etapa de la Edad del Hierro.

\footnotetext{
77 Alfredo González-Ruibal y Xulio Carballo Arceo, "Cerámicas de Castrovite (A Estrada, Pontevedra)", Boletín Auriense, 31 (2001), pags. 35-82.

${ }^{78}$ Maria João Correia SANTOS, “Santuarios rupestres no...”, págs. 153-154.
} 
Volviendo a nuestro argumento, a la segunda Edad del Hierro corresponde la ocupación de San Cibrán, como hemos visto, momento en el que posiblemente estaba en uso A Ferradura. En este sentido A Ferradura, la croa de San Cibrán y el conjunto de Santa Mariña se pueden entender como áreas rituales complementarias, a pesar del diferente uso de las topografías naturales, de sus distintas formas de monumentalización y de sus diversas historias. De la misma forma que en cualquier otra religión politeísta coexisten formas de lugares de culto variadas sea por los dioses conmemorados o por el tipo de actividades desarrollado.

Para terminar, si consideramos el conjunto de la exposición creemos que es posible atribuir un significado ritual a las pilas de Santa Mariña que deriva de su origen antrópico completado por la continuidad de uso simbólico-religioso del lugar. Pensamos que esa continuidad es un indicio de su función cultual en tiempos anteriores. Lo que permanece como hipótesis es la existencia de una suerte de estratigrafía interna de las estructuras estudiadas. Simplemente hemos argüido a favor de la toma en consideración de esta posibilidad mediante su inserción en el contexto más amplio que forma el paisaje arqueológico del Barbantiño.

\section{Conclusión: Tipología Y ESTUdio de CASOS}

Para concluir quisiéramos destacar la necesidad de seguir profundizando en el estudio de la actividad de los habitantes de los castros en el exterior de sus residencias. Es un campo novedoso en donde, por lo tanto, es fácil cometer errores de apreciación que sólo el tiempo dirá que lo son. Una faceta de estas actividades tenía, con toda probabilidad, una dimensión religiosa con rasgos que desconocemos en el detalle pero que conocemos relativamente bien como actividades religiosas propias de muy diferentes culturas de la protohistoria y la antigüedad: romerías, procesiones, asambleas, lugares de iniciación, de celebración de sacrificios, en tiempos fijados o aleatorios, etc.

También hemos presentado una tipología de los lugares de función ritual en la Edad del Hierro que sólo el avance de los estudios dirá si es pertinente o señalará las modificaciones que pueda precisar. Pero sugerimos que puede ser útil, al menos de forma provisional, para intentar acostumbrar la mirada a detectar y a interpretar elementos arqueológicos que han permanecido largo tiempo ignorados por falta, precisamente, de unos marcos de comprensión mínimos.

Naturalmente esa tipología sólo puede ser orientativa y cada caso concreto va a presentar un conjunto de rasgos que lo hacen único. Esto es lo que hemos intentado hacer en nuestro examen del castro de Santa Mariña de Maside. Pero lo que permite avanzar el conocimiento es la búsqueda de un equilibrio entre la acumulación de estudios de casos singulares y el ensayo de identificar pautas generales: esta es la tarea que proponemos. 


\section{BIBLIOGRAFÍA}

Aboal-Fernández, Roberto, Ayán Vila, Xurxo Miguel y Prieto Martínez, María Pilar, "El área arqueológica de O Peto (Vedra, A Coruña, Galicia): ¿posible explotación minerometalúrgica prerromana?", Era-Arqueologia, 5 (2003), págs. 104-123.

Alfayé Villa, Silvia, Santuarios y rituales en la Hispania Céltica, Oxford, Archaeopress, 2009 (BAR-International Series, 1963).

Almagro-Gorbea, Martín, "La triple muerte en el Libro del Buen Amor y la leyenda de Santa Mariña de Aguas Santas", en Martín Almagro-Gorbea, Literatura hispana prerromana. Creaciones literarias fenicias, tartesias, iberas, celtas y vascas, Madrid, Real Academia de la Historia, (2013), págs. 376-413.

Alonso Romero, Fernando, "La figura de mujer del petroglifo da Pena Furada (Figueiras, Santa Mariña de Lesa, Coirós, A Coruña)”, Anuario Brigantino, 27 (2004), págs. 161-178.

Álvarez González, Yolanda, López González, Luis, López, Miguel Ángel y López Barja, Pedro, "Dos inscripciones inéditas del castro de San Cibrán de Las (San Amaro-Punxín, Ourense)”, Paleohispánica, 4 (2004), págs. 235-244.

Álvarez González, Yolanda, López González, Luis y López, Miguel Ángel, “La ocupación del espacio común y privado en la citania de San Cibrán de Lás”, Revista Aquae Flaviae, 41 (2009), págs. 195-209 (Actas del congreso transfonteiriço de Arqueología, 3-5 Octubre 2008-Montealegre).

Arcelin, Patrice y Brunaux, Jean-Louis. "Un état des questions sur les sanctuaires et les pratiques cultuelles de la Gaule Celtique", Gallia, 6 (2003), págs.1-268.

Ayán Vila, Xurxo Miguel, Rodríguez Martínez, Rafael María, González-Ruibal, Alfredo, González Pérez, Leonardo, Arizaga Castro, Álvaro y Franco Fernández, Manuel A., "Un espacio monumental de la $2^{\mathrm{a}}$ Edad del Hierro: el acceso $\mathrm{SE}$ al recinto superior de O Castro Grande de Neixón (Boiro, A Coruña)", en A. Fanjul Peraza (coord.), Estudios Varios de Arqueología Castreña, Teverga, Instituto de Estudios Prerromanos y de la Antigüedad, 2007, págs. 189-209.

Arizaga Castro, Álvaro y Ayán Vila, Xurxo Miguel, "Etnoarqueología del paisaje castreño: la segunda vida de los castros", en F.J. González García (ed.), Los pueblos de la Galicia Céltica, Akal, Madrid, 2007, págs. 445-531.

Barandela Rivero, Israel y Lorenzo Rodríguez, José Manuel, Petroglifos de Ourense, Reflexións a un primeiroreconto da arte rupestre prehistórica na provincia de Ourense, $\mathrm{Ou}-$ rense, Diputación provincial de Ourense, 2004.

Barandela Rivero, Israel y Lorenzo Rodríguez, José Manuel, "El culto a Santa Mariña en el norte de la Península Ibérica y sus conexiones conla Europa Atlántica", Porta da aira: revista de historia del arte orensano, 13 (2011), págs. 117-143.

Barandela Rivero, Israel, Castro Pérez, Ladislao, Lorenzo Rodríguez, José Manuel y Otero, Rafael, "Notas sobre los santuarios rupestres de la Gallaecia", Minius, 13 (2005), págs. 47-68.

Bermejo Barrera, José Carlos, Sociedade e Relixión na Galicia Antigua, Santiago, Lóstrego, 2008.

Brulé, Pierre, "Le sanctuaire est un sanctuaire", Bandue, 4 (2010), págs. 25-65. 
Búa Carballo, Juan Carlos, "Hipótesis para algunas inscripciones rupestres del Occidente Peninsular”, en F. Villar y F. Beltrán (eds.), Pueblos, Lenguas y Escrituras en la Hispania Prerromana, Salamanca, Ed. Universidad de Salamanca, 1999, págs. 309-327.

Calo Lourido, Francisco, Os celtas: unha (re)visión dende Galicia, Vigo, Edicións Xerais de Galicia, 2010.

De Bernardo-Stempel, Patricia y García Quintela, Marco Virgilio, "Población trilingüe y divinidades del castro de Lansbriga (NO de España)", Madrider Mitteilungen, 49 (2008), págs. 254-290.

Diego Santos, Francisco, Epigrafía romana de Asturias, Oviedo, Ed. Universidad de Salamanca, 1984.

Dominguez-Villar, David, Arteaga, Carlos, García-Gimenez, Rosario, Smith, Eric y Pedraza Gilsanz, Javier De, "Diurnal and seasonal water variations of temperature, $\mathrm{pH}$, redoxpotential and conductivity in gnammas (weatheringpits): Implications for Chemicals Weathering", Catena, 72 (2008), págs. 37-48.

Domínguez-Villar, David, Razola, Laura, Carrasco, Rosa, Jennings, C. y Pedraza Gilsanz, Javier De, "Weathering phases recorded by gnammas developed since last glaciation at Serra da Estrela, Portugal”, Quaternary Research, 72 (2009), págs. 218-228.

Dupré Raventos, Xavier, Ribichini, Sergio y Verger, Stephano, Saturnia Tellus. Definizioni dello spazio consacrato in ambienteetrusco, italico, fenicio-punico, iberico e céltico. Actas del congreso internacional (10-12 noviembre 2004-Roma), Roma, Consiglio Nazionale delle Ricerche, 2008, págs. 12-26.

Estévez Puga, Xosé, et al., Maside e a súa antiga xurisdición, Ourense, Concello de Maside, 1994.

Fernández De La Cigoña, Estanislado, O Aceite en Galicia. Guía das Lagaretas CastrexoRomanas, Medievais e Modernas, Vigo, Asociación Galega para a Cultura e a Ecoloxía; Instituto Galego de Estudos Mariños, 2003 (Col. Etnografía Galega).

Fernández Malde, Antón, "Petroglifos da Pena Furada (Figueiras, Coirós)", Anuario Brigantino, 16 (1993), págs. 15-24.

Fernández Posse, María Dolores y Sánchez Palencia, Francisco Javier, "Las comunidades campesinas en la Cultura Castreña”, Trabajos de Prehistoria, 55-2 (1998), págs. 127-150.

García Alonso, Juan Luis, La Península Ibérica en la Geografía de Claudio Ptolomeo. Vitoria-Gasteiz, Universidad del País Vasco, 2003.

García Quintela, Marco Virgilio, "Sociedad y Religión en la Galicia Antigua: una historia del tiempo abolido", Gerión, 27, vol. 2 (2009), págs. 79-105.

García Quintela, Marco Virgilio, "Mariña concubina, Mariña virgen, Boand adúltera: fecundidad extramarital y genealogía de los paisajes", en M $M^{\mathrm{a}}$ Tausiet, H. Tropé (eds.), Folclore y leyendas en la península ibérica. En torno a la obra de François Delpech, [en prensa].

García Quintela, Marco Virgilio y Santos Estévez, Manuel, Santuarios de la Galicia Céltica, Madrid, Abada, 2008.

García Quintela, Marco Virgilio y Seoane-Veiga, Yolanda, "La larga vida de dos rocas ourensanas”, Archivo Español de Arqueología, 84 (2011), págs. 243-266.

García Quintela, Marco Virgilio y Seoane-Veiga, Yolanda, "Entre Naturaleza y Cultura: Arquitectura ambigua en la Edad del Hierro del NO peninsular", [en prensa]. 
Glinister, Fay, "What is a sanctuary?", Cahiers du Centre Gustave Glotz, 8 (1997), págs. 61-80.

González García, Francisco Javier, "Los pueblos de la Galicia Céltica”, Madrid, Akal, 2007.

González-Ruibal, Alfredo, Galaicos. Poder y comunidad en el Noroeste de la Península Ibérica (1200 a. C.-50 d. C.), 2 vols., A Coruña, Brigantium, 2006-2007.

González-Ruibal, Alfredo y Carballo Arceo, Xulio, "Cerámicas de Castrovite (A Estrada, Pontevedra)", Boletín Auriense, 31 (2001), pags. 35-82.

González-Ruibal, Alfredo, Rodríguez Martínez, Rafael María y Ayán Vila, Xurxo Miguel, "Buscando a los Púnicos en el Noroeste", Mainake, 32-1 (2010), págs. 577-600.

Ingold, Tim, "Materials against materiality", Archaeological Dialogues, $14-1$ (2007), págs. 1-16.

Kylander, Malin E., Weiss, Dominik J, Martínez Cortizas, Antonio, Spiro, Baruch, GarcíaSánchez, R. y Coles, Barry, "Refining the pre-industrial atmospheric Pb isotope evolution curve in Europe using and 8000 year old peat core from NW Spain", Earth and Planetary Science Letters, 240 (2005), págs. 467-485.

Koch, Michael, "El Santuario dedidado a Berobreo en el Monte do Facho (Cangas, Galicia)". Palaeohispánica, 5 (2005), págs. 823-836.

Lambert, Pierre-Yves, "Gauloisnemeton et atośdeuogdonion: deuxnoms de l'espacesacré"en X. Dupré et al., Saturnia Tellus. Definizioni dello spazio consacrato in ambiente etrusco, italico, fenicio-punico, iberico e céltico. Actas del congreso internacional (10-12 noviembre 2004 - Roma), Roma, Consiglio Nazionale delle Ricerche, 2008, págs. 133-149.

Linderski, Jerzy “The Augural Law”, ANRW, II/16/3 (1986), págs. 2146-2312.

Loscertales de G. de Valdeavellano, Pilar, Tumbos del Monasterio de Sobrado de los Monjes, 2 vols., Madrid, Ed. Archivo Histórico Nacional, 1976.

Mac Giolla Easpaig, Dónall, "Ireland 's heritage of geographical names”, Wiener Schriftenzur Geographie und Kartographie, 18 (2009), págs.79-85.

Marco Simón, Francisco, "Romanización y aculturación religiosa: los santuarios rurales", en Susana Reboreda y Pedro López Barja (eds.), A cidade e o mondo: Romanización e cambio social, Xinzo de Limia, Concello, 1996, págs. 81-100.

Martínez Cortizas, Antonio; García-Rodeja, Eduardo; Pontevedra Pombal, Xabier; Nóvoa Muñoz, Juan Carlos; Weiss, Dominik y Cheburkin, Andriy, "Atmospheric Pb deposition in Spain during the last 4600 years recorded by two ombrotrophic peat bogs and implications for the use of peat as archive", Science of the Total Environment, 292 (2002), págs. 33-44.

Monteagudo García, Luis, "La religiosidad gallaica: estela funeraria romana de Mazarelas (Oza dos Ríos, A Coruña), cultos astrales, priscilianismo y outeiros", Anuario Brigantino, 19 (1996), págs. 11-118.

López Cuevillas, Florentino, "Sobre la mitología y las costumbres relativas a tres pilas megalíticas del Ribeiro de Avia", Cuadernos de Estudios Gallegos, 9 (1954), págs. 181-191.

López Cuevillas, Florentino y Lorenzo Fernández, Joaquín, "Cuatro peñas con pilas, del sur de Galicia", Cuadernos de Estudios Gallegos, 7 (1952), págs. 5-54.

López González, Luis Francisco y Álvarez González, Yolanda, "La secuencia cultural del asentamiento de Laias: evolución espacial y funcional del poblado", Proto-historia da Península Ibérica. ADECAP (2001), págs. 523-530. 
Parcero-Oubiña, César, Criado-Boado, Felipe y Santos Estévez, Manuel, Rewriting landscape: incorporating sacred landscapes into cultural traditions", World Archaeology, 30-1 (1998), págs. 159-176.

Parcero-Oubiña, César, La Arqueología en la Gasificación de Galicia 7: Hacia una Arqueología Agraria de la Cultura Castreña, Santiago de Compostela, Grupo de Investigación de Arqueología del Paisaje, Universidad de Santiago de Compostela, 1998 (Traballos de Arqueoloxía da Paisaxe, TAPA, 9)

Parcero-Oubiña, César, La construcción del Paisaje Social en la Edad del Hierro del Noroeste Ibérico, Ortigueira, Fundación Ortegalia, 2002.

Peralta Bejareno, Isabel, Rodríguez González, Xulio y Xusto Rodríguez, Manuel, Conjunto arqueológico-natural de Santomé: excavación, consolidación y musealización de un sector del Castro, A Coruña, Fundación Pedro Barrié de la Maza, 2004.

Pedley John G., Sanctuaries and the sacred in the ancient Greek world / New York, Cambridge, University Press, 2005.

Rodríguez Colmenero, Antonio, Galicia meridional romana, Bilbao, Ed. Universidad de Deusto, 1977.

Rodríguez Colmenero, Antonio, “Corpus-Catálogo de inscripciones rupestres de época romana del cuadrante Noroeste de la Península Ibérica", en Antonio Rodríguez Colmenero y Lido Gasperini (eds.), Saxa Scripta (Inscripciones en Roca). Actas del Simposio Internacional Ibero-Itálico sobre Epigrafia Rupestre, Santiago de Compostela y Norte de Portugal, 1992, La Coruña, Edicions do Castro, 1995 (Anejos de Larouco, 2).

Rodríguez Colmenero, Antonio, O santuario rupestre Galacio-Romano de Panoias (Vila Real, Portugal). Novas achegas para a sua reinterpretaçao global, Vila Real, Breogán, 1999.

Ruiz Zapatero, Gonzalo y Álvarez-Sanchís, Jesús R., "Ulaca la Pompeya Vettona”, Revista de Arqueología, 216 (1999), págs. 36-47.

Santos Estévez, Manuel, "Los espacios del arte: el diseño del panel y la articulación del paisaje en el arte rupestre gallego", Trabajos de Prehistoria, 55, núm. 2 (1998), págs. 73-88.

Santos Estévez, Manuel, "Sobre la cronología del Arte Rupestre Atlántico en Galicia", Arqueoweb 7/2 (2005) [en línea], disponible en <http://www.ucm.es/info/arqueoweb/pdf/72/santos.pdf>

Santos Estévez, Manuel, Petroglifos y paisaje social en la prehistoria reciente del Noroeste de la Península Ibérica, Santiago de Compostela, Laboratorio de Arqueoloxía-Instituto de Estudios Gallegos "Padre Sarmiento", CSIC, 2008 (Traballos de Arqueoloxía e Patrimonio, TAPA, 38).

Santos Estévez, Manuel y SeoaneVeiga, Yolanda, "Escavación no contorno dun petroglifo en A Ferradura", Arkeos: Arte Rupestre, Pre-historia, Patrimonio, 5 (2004), págs. 37-55.

Santos, Maria João Correia, "Santuarios rupestres no occidente da Hispania indo-europeia. Ensaio de tipologia e clasifiçao", Palaeohispanica, 10 (2010), págs. 147-172.

Santos, Maria João Correia, "Inscripciones rupestres y espacios sagrados del norte de Portugal: nuevos datos y contextualización”, en J. Alberto Arenas-Esteban (ed.), Celtic Religion across Space and Time. IX Workshop F.E.R.C.AN. Fontes Epigraphici Religionum celicarum Antiquarum, Toledo, Junta de Comunidades Castilla-La Mancha, 2010. 
Santos, Maria João Correia, "O Cabeço de Fráguas e a concepçâo de espaço sagrado na Hispania indo-europeia”, Iberografias, 6 (2010), págs. 131-141.

Santos, Maria João Correia, "La arqueología, lo imaginario y lo real. El santuario rupestre de Mogueira (Sâo Martinho de Mouros, Portugal)", Madrider Mitteilungen [en prensa] .

Sastre Prats, Inés, Las formaciones sociales rurales de la Asturia Prerromana, Madrid, Ediciones Clásicas, 2001.

Schattner, Thomas, Suárez Otero, José y Koch, Michael, "Monte do Facho (O Hío, prov. Pontevedra) 2004: informe sobre las excavaciones en el Santuario de Berobreo", Palaeohispánica, 6 (2006), págs. 183-223.

Scheid, John, "Commentidentifier un lieu de culte?", Cahiers du Centre Gustave Glotz, 8 (1997), págs. 51-59.

Seoane-Veiga, Yolanda, Prieto Martínez, María Pilar y Dal Zovo, Cecilia,"Bell beaker findings in rock art contexts", en María Pilar Prieto Martínez y Laure Salanova (coords), Current researches on Bell Beakers. (Proceedings of the $15^{\text {th }}$ International Bell Beaker Conference: From Atlantic to Ural. $5^{\text {th }} 9^{\text {th }}$ May 2011 Poio, Pontevedra, Galicia, Spain), Santiago de Compostela, Galician Archaeo Pots, 2013, págs. 31-40.

Silva, Armando Coelho da (coord.), Pedra formosa: arqueologia experimental, [Vila Nova de Famalicão], Câmara Municipal de Vila Nova de Famalicão; Museu Nacional de Arqueologia, 2007.

Villa Valdés, Ángel y Cabo Pérez, Luis, "Depósito funerario y recinto fortificado de la Edad del Bronce en el Castro del Chao de Sanmartín: argumentos para su datación", Trabajos de Prehistoria, 60-2 (2003), págs. 143-151.

Villa Valdés, Ángel, "Saunas castreñasenpoblados fortificados de Asturias y Galicia”, en A. Coelho (Coord.), Pedra formosa: arqueologia experimental, [Vila Nova de Famalicão], Câmara Municipal de Vila Nova de Famalicão; Museu Nacional de Arqueologia, 2007.

Villa Valdés, Ángel, "Santuarios urbanos en la protohistoria cantábrica: Algunas consideraciones sobre el significado y la función de las saunas castrexas", Boletín del Real Instituto de Estudios Asturianos, 177 (2012), págs. 9-47. 